\title{
Analysis of MJO Wind-Flux Feedbacks in the Indian Ocean Using RAMA Buoy Observations
}

\author{
Emily M. RILEY DELLARIPA and Eric D. MALONEY \\ Department of Atmospheric Science, Colorado State University, Colorado, USA \\ (Manuscript received 9 September 2014, in final form 27 November 2014)
}

\begin{abstract}
Observations spanning 2004-2012 from two Research Moored Array for African-Asian-Australian Monsoon Analysis and Prediction (RAMA) buoys along the equator in the Indian Ocean are used in conjunction with Tropical Rainfall Measuring Mission (TRMM) to assess the relative importance of surface latent heat fluxes to intraseasonal convection. This work is motivated by previous observational and modeling studies that have suggested the importance of wind-induced surface fluxes to the dynamics of the Madden-Julian Oscillation (MJO).

Intraseasonal variability is isolated in two ways: 1) 20-100-day bandpass filtering and 2) using the global real time multivariate MJO index. Linear regression shows latent heat flux anomalies to be between $4 \%$ and $8 \%$ of precipitation anomalies when the two variables are compared using similar $\mathrm{Wm}^{-2}$ energy units. From a moist static energy budget viewpoint, these results confirm the potential of wind-induced latent heat fluxes to aid destabilization of MJO convection. Results derived from using both simple intraseasonal filtering and global MJO indices indicate that precipitation leads latent heat flux on the order of a few days, indicating surface fluxes may be more important for maintenance of deep MJO convection in addition to helping set the MJO's propagation speed. Sensitivity tests using smoothed wind speed or thermodynamics (i.e., air temperature, relative humidity, and sea surface temperature) to compute latent heat flux show wind speed variability explains most of the latent heat flux variability on intraseasonal timescales. A similar conclusion is found via linearization of the latent heat flux formula. Additional analysis shows mesoscale and synoptic scale wind variability have negligible impact on intraseasonal latent heat flux anomalies.
\end{abstract}

Keywords Madden-Julian Oscillation; intraseasonal oscillation; surface flux; wind speed; precipitation; MSE; Indian Ocean; buoy

\section{Introduction}

Observationally, the Madden-Julian Oscillation (MJO) is well described as the dominant mode of tropical intraseasonal (30-90 days) variability consisting of a large envelope $(\mathrm{O}(1000 \mathrm{~km}))$ of multiscale convective cloud elements (e.g., Naka-

Corresponding author: Emily M. Riley Dellaripa, Department of Atmospheric Science, 1371 Campus Delivery, Colorado State University, Fort Collins, Colorado 80523, USA

E-mail: emily@atmos.colostate.edu

(C)2015, Meteorological Society of Japan zawa 1995) that frequently, but not always, initiates over the Indian Ocean (e.g., Salby and Hendon 1994; Matthews 2008) and propagates slowly eastward (approximately $5 \mathrm{~m} \mathrm{~s}^{-1}$; Madden and Julian 1972 and Zhang 2005 and references therein). The precipitation decays over the central Pacific, while the wind and moisture signals associated with the MJO continue to circumnavigate the globe (e.g., Knutson and Weickmann 1987; Kikuchi and Takayabu 2003; Kiladis et al. 2009; Haertel et al. 2014).

From an Eulerian perspective, as the canonical MJO evolves from suppressed to active convective conditions, low-level wind transition from easterly 
to westerly (with opposite signed upper level winds), low-level moisture builds vertically, and the fractional contribution of various cloud types shift (e.g., Lin and Johnson 1996; Kiladis et al. 2005; Benedict and Randall 2007; Powell and Houze 2013; Johnson and Ciesielski 2013). Narrow deep convective clouds along with shallow convection give way to wide (more organized) convection followed by anvil clouds (Morita et al. 2006; Riley et al. 2011; Powell and Houze 2013; Barnes and Houze 2013; Zuluaga and Houze 2013; Xu and Rutledge 2014). While general circulation models (GCMs) have been able to reproduce these observed characteristics of the MJO with varying degrees of success (e.g., Grabowski 2003; Maloney and Sobel 2004; Benedict and Randall 2009; Kim et al. 2009; Maloney et al. 2010; Chikira 2014), no consensus exists on a theory that completely explains the spatial scale, initiation and propagation of the MJO. As such, the MJO remains an ideal target phenomenon to further understanding convective and large-scale interactions and the importance of air-sea coupling.

This paper focuses on one piece of the MJO puzzle - the role of surface fluxes in destabilizing MJO convection, specifically over the Indian Ocean. This work builds from previous observational and modeling work (i.e., Maloney and Esbensen 2005 and 2007; Back and Bretherton 2005; Araligidad and Maloney 2008; Maloney 2009; DeMott et al. 2014) that has suggested the importance of wind-induced fluxes for destabilizing the MJO, and supports a recent body of work referred to as moisture mode theory (e.g., Raymond and Fuchs 2007, 2009; Sugiyama 2009a, b; Sobel et al. 2010; Sobel and Maloney 2012).

\subsection{Brief background on WISHE and moisture mode theory}

The original linear theory of Wind-Induced Surface Heat Exchange (WISHE; Neelin et al. 1987; Emanuel 1987) proposed that a positive feedback between wind, surface fluxes, and convection could initiate and maintain the MJO. While the details of the original theory have been disproven given that the active conditions of the MJO, with deep organized convection, are accompanied by anomalous low-level westerlies (e.g., Lin and Johnson 1996) as opposed to easterlies as the theory predicted, the general idea of surface flux feedbacks being important to MJO destabilization has not been disproven as emphasized in a review article by Sobel et al. (2010).

The moisture mode theory of the MJO highlights the context in which the interactions between intraseasonal latent heat flux (LHFLX) and precipitation anomalies may be important. The theory works under the assumption of weak temperature gradients (WTG) in the tropics in which temperature tendencies are assumed to be negligible to first order (Sobel and Bretherton 2000; Sobel et al. 2001). As the theory's name suggests, convective dynamics are then controlled by processes that regulate free-tropospheric moisture. These regulatory processes include cloud radiative feedbacks and surface flux feedbacks.

The stability of the mode can be evaluated using column integrated moist static energy budgets (MSE; $m=c_{p} T+g z+L_{\nu} q$, where $c_{p}$ is specific heat at constant pressure, $T$ is temperature, $g$ is gravity, $z$ is height above the ground, $L_{v}$ is the latent heat of vaporization, and $q$ is specific humidity). MSE anomalies are equivalent to latent heat anomalies under WTG theory, and hence MSE budgets can be used to diagnose the dynamics of a moisture mode (e.g., Maloney 2009; Hannah and Maloney 2011; Andersen and Kuang 2012; Chikira 2014). Similar to previous works (i.e., Back and Bretherton 2005; Hannah and Maloney 2011) the vertically integrated MSE budget is

$$
\begin{aligned}
& \left\langle\frac{\partial m}{\partial t}\right\rangle=-\langle\vec{V} \cdot \nabla m\rangle-\left\langle\omega \frac{\partial m}{\partial p}\right\rangle+L H+S H \\
& \quad+\langle L W\rangle+\langle S W\rangle,
\end{aligned}
$$

where the first two terms on the right hand side represent the column integrated horizontal and vertical advection, respectively. The third and fourth terms in (1) are surface latent and sensible heat fluxes, while the last two terms are the column integrals of longwave and shortwave radiation, respectively. When enhanced MJO convection occurs, the sum of column processes, horizontal advection, and MSE sources (e.g., surface fluxes and radiation) should be positive to support moisture anomalies and maintain the MJO (e.g., Back and Bretherton 2005; Raymond et al. 2009). Physically, increases in column MSE (via surface fluxes and radiation) are partially balanced by divergent motions from deep convection, which export MSE from the column. Dry air advection may also be a sink of MSE, but Sobel and Maloney (2013) argued that the covariance between dry air advection and precipitation is minimized for large-scale disturbances such as the MJO. Surface fluxes may destabilize the column by increasing boundary layer (BL) moisture and MSE, allowing conditional instability to be realized and convection to develop (e.g., Back and 
Bretherton 2005). Increases in surface fluxes may also be communicated to the free troposphere via ubiquitous shallow convection, which transports moisture vertically from the BL.

A highly idealized theoretical analysis of Yu et al. (1998) suggested that the export of column MSE by vertical motions associated with deep convection occurs at a rate of approximately $20 \%$ of precipitation over the west Pacific warm pool and southeast Indian Ocean and at a rate of approximately $14 \%$ of precipitation near the Maritime Continent. In more recent findings, Sobel et al. (2014) showed vertical advection discharges column MSE at a rate of 10 $\%-20 \%$ of precipitation at the peak of the CINDY/ DYNAMO (i.e., Cooperative Indian Ocean Experiments on Intraseasonal Variability in the Year 2011; Dynamics of the MJO) field campaign (Yokoi et al. 2014; Moum et al. 2013). We note that in both $\mathrm{Yu}$ et al. (1998) and Sobel et al. (2014) precipitation was converted to energy units to compute the ratio of MSE discharge from vertical motions associated with convection. If the ratio of surface fluxes to precipitation is a substantial fraction of these values during active MJO events, then the conclusion could be made that surface fluxes are important for maintaining MJO convection as surface fluxes would counteract a large portion of the MSE discharge associated with vertical motions in deep convection areas. While convective-radiation feedbacks may also counteract MSE discharge; we leave the quantification of radiative feedbacks to the MSE budget for future work. Therefore, the primary goal of this work is to quantify the surface flux to precipitation ratio over the Indian Ocean during intraseasonal events. Surface fluxes and precipitation will be compared in equivalent energy units $\left(\mathrm{W} \mathrm{m}^{-2}\right)$ in order to diagnose the relevance of surface fluxes to the rate at which precipitation discharges MSE. Once the role of surfaces fluxes is established, the mechanisms driving those intraseasonal surface fluxes are evaluated.

\subsection{Previous works supporting the importance of surface fluxes to the MJO}

Maloney and Esbensen (2003) noted the plausible importance of LHFLX anomalies to the feedback between MJO convection and the low-level circulation in the east Pacific warm pool. Subsequent model simulations by Maloney and Sobel (2004) and Maloney and Esbensen (2005) further supported the importance of surface fluxes to intraseasonal convection both in the Indo-Pacific warm pool and the east Pacific. Maloney and Sobel (2004) found that wind-induced flux variability in their GCM simulations was necessary to produce realistically large intraseasonal precipitation amplitude. This result was reproduced by Maloney and Esbensen (2005) for the east Pacific warm pool. In GCM mechanism denial experiments, Sobel et al. (2008, 2010) and Maloney et al. (2010) demonstrated that removing intraseasonal flux variability strongly diminished tropical intraseasonal variability. Also, when examining the vertically integrated intraseasonal MSE budget in a GCM, Maloney (2009) found that LHFLXs and horizontal advection of MSE were the two dominant terms although the importance of LHFLX as a destabilization mechanism is strongly model dependent (e.g., Andersen and Kuang 2012).

On a tropics wide scale, Back and Bretherton (2005) showed a positive correlation between precipitation and latent heat flux anomalies, especially in regions of high specific humidity. Araligidad and Maloney (2008; hereafter AM08) and Maloney and Esbensen (2007) found a similar positive correlation at intraseasonal timescales using Tropical Ocean Global Atmosphere (TOGA) Tropical Atmosphere Ocean (TAO) buoy data and Tropical Rainfall Measuring Mission (TRMM) rainfall measurements over the west and east Pacific, respectively. Additionally, Kiranmayi and Maloney (2011) showed a positive covariance between reanalysis precipitation and surface fluxes. Maloney and Esbensen (2005) showed in both observational and model results that east Pacific intraseasonal latent heat flux anomalies are about $10 \%$ of intraseasonal precipitation anomalies (their Fig. 11). AM08 found a slightly higher ratio from observations in the west Pacific - intraseasonal LHFLX anomalies were between $18 \%-24 \%$ of intraseasonal precipitation anomalies.

The importance of surface fluxes over the Indian Ocean relative to MJO convection was analyzed during the CINDY/DYNAMO field campaign. Yokoi et al. (2014) focused on surface fluxes associated with sub-mesoscale convection. By examining the evolution of fluxes from pre-convective to convective to recovery MJO periods, they concluded that both sensible and latent heat fluxes contributed to the overall increase in surface fluxes during convective periods, though LHFLX more so than sensible heat flux. Additionally, they noted LHFLXs were more wind-driven while sensible heat fluxes were driven more by air-sea temperature differences. Using observations from the R/V Revelle (nominally located at $0^{\circ}, 80.5^{\circ} \mathrm{E}$ ) and the $0^{\circ}, 80.5^{\circ} \mathrm{E}$ RAMA (Research Moored Array for African-Asian-Austra- 
lian Monsoon Analysis and Prediction) buoy during CINDY/DYNAMO, Moum et al. (2013) found that the arrival of MJO active phases were related to westerly wind bursts and an increase in surface latent heat fluxes, which helped the ocean surface transition from a net heating to a net cooling as the MJO evolved from suppressed to active conditions (their Figs. 2, 7). Additionally, Sobel et al. (2014), using DYNAMO sounding observations, found surface fluxes to be important to the MSE budget for the October and November 2011 MJO events, despite radiative fluxes being the dominant term.

We extend the observational analysis of AM08 and Maloney and Esbensen (2007) to the Indian Ocean using the RAMA and TRMM precipitation measurements. Extending previous LHFLX vs. precipitation analyses, but for the Indian Ocean, is warranted since the Indian Ocean is the main area of MJO initiation and development (e.g., Salby and Hendon 1994; Matthews 2008). DeMott et al. (2014) argue that Indian Ocean air-sea coupled processes are critical for the subsequent global evolution of the MJO. Additionally, it is important to assess if and how the LHFLX vs. precipitation relationship changes as the MJO propagates eastward across the Indian Ocean to the Pacific Ocean. This work compliments CINDY/ DYNAMO studies by not only overlapping with the campaign time period but also by extending the analysis of fluxes to time periods substantially before and after the campaign.

The following section describes the data and methods. Section 3 shows the relationship between intraseasonal Indian Ocean latent heat flux anomalies and precipitation anomalies. Section 4 examines the dynamic and thermodynamic controls of LHFLX. Section 5 briefly mentions supporting analysis that verifies results shown in Sections 3 and 4. Section 6 discusses the implication of the results and Section 7 concludes the paper.

\section{Data and methods}

\subsection{RAMA buoy data}

The RAMA buoy array consists of 23 operational moored buoys in the Indian Ocean basin $(\mathrm{McPh}-$ aden et al. 2009, http://www.pmel.noaa.gov/tao/ rama). Two buoys along the equator at $80.5^{\circ} \mathrm{E}$ and $90^{\circ} \mathrm{E}$ were subjectively chosen to use in this study based on their continuity of high time resolution data compared to other RAMA buoys, and their location in a region relevant to MJO dynamics (e.g., Salby and Hendon 1994; Matthews 2008; Yoneyama et al. 2013). Of all the RAMA buoys, the $0^{\circ}, 90^{\circ} \mathrm{E}$ buoy has the largest amount of high-resolution data needed to compute surface fluxes. The $0^{\circ}, 80.5^{\circ} \mathrm{E}$ buoy has about $60 \%$ of the amount of data that the $0^{\circ}, 90^{\circ} \mathrm{E}$ buoy has, but was chosen for analysis because it sits along the same latitude as the $90^{\circ} \mathrm{E}$ buoy. We also examine results from the $8^{\circ} \mathrm{S}, 80.5^{\circ} \mathrm{E}$ buoy in Section 6 and contrast results from this off-equatorial buoy to those from the equatorial buoys. We will simply distinguish the two equatorial buoys by their longitude for the remainder of the paper. Both buoys are ATLAS (autonomous temperature line acquisition system) moorings deployed by the National Oceanographic and Atmospheric Administration Pacific Marine Environmental Laboratory (NOAAPMEL) in collaboration with the Indian National Institute of Oceanography (NIO) and the Indian Ministry of Earth Sciences in 2004. Both moorings measure air temperature $(\mathrm{T})$, relative humidity $(\mathrm{RH})$, wind velocity, downwelling shortwave (SW) radiation and rain between 3 and $4 \mathrm{~m}$ above mean sea level, and sea surface temperature (SST) at $1 \mathrm{~m}$ below the sea surface (McPhaden et al. 2009). Rainfall is measured with a self-siphoning rain gauge (Serra et al. 2001). The $80.5^{\circ} \mathrm{E}$ mooring additionally records downwelling longwave (LW) radiation and barometric pressure (McPhaden et al. 2009). We used the high-resolution meteorological and radiation data collected at 10- and 2-minute intervals, respectively. The LW and SW radiation data were re-binned to 10-minute resolution to be consistent with the meteorological variables.

The TOGA Coupled Ocean-Atmosphere Response Experiment (COARE) flux bulk algorithm version 3.0 was used to compute surface LHFLX and sensible heat fluxes (SHFLX; Fairall et al. 2003) from the 10 minute fields. The flux algorithm contains sub-models that calculate the cool skin and warm layer ocean temperatures to estimate the actual sea surface interface (vs. $1 \mathrm{~m}$ depth) temperature (Fairall et al. 2003). Both LW and SW radiation are inputs to these submodels. However, since the $90^{\circ} \mathrm{E}$ buoy has no LW information, the LW radiation correction was neglected for both buoys when calculating LHFLX and SHFLX. Comparing LHFLX and SHFLX computed with and without LW radiation for the $80.5^{\circ} \mathrm{E}$ buoy revealed little change in final values $-\mathrm{O}\left(1 \mathrm{~W} \mathrm{~m}^{-2}\right)$ and $\mathrm{O}\left(0.1 \mathrm{~W} \mathrm{~m}^{-2}\right)$ for LHFLX and SHFLX, respectively (not shown). In extreme cases, neglecting the LW correction cause a substantial change in LHFLX and SHFLX values with a difference of 15 and $3 \mathrm{~W} \mathrm{~m}^{-2}$, respectively. However, the importance of these few times with substantial differ- 

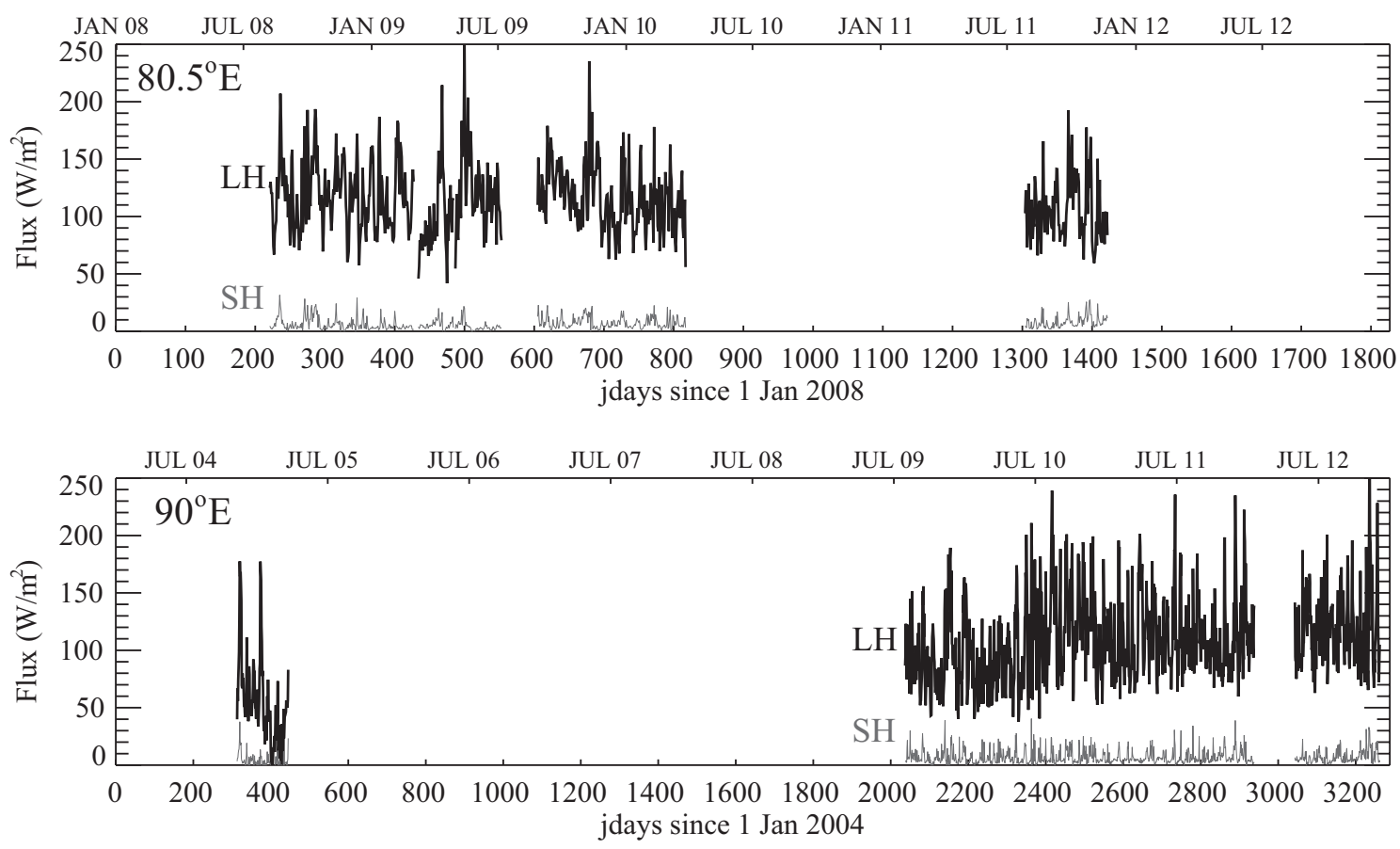

Fig. 1. LHFLX and SHFLX for the $80.5^{\circ} \mathrm{E}$ (top panel) and $90^{\circ} \mathrm{E}$ (bottom panel) buoys.

ences is diminished on the intraseasonal timescale, and our results are not sensitive to the LW correction. Surface flux output from the algorithm was averaged to daily timescales.

Figure 1 shows the time series of daily averaged surface fluxes for the $80.5^{\circ} \mathrm{E}$ buoy from 2008 to 2012 and from 2004 to 2012 for the $90^{\circ} \mathrm{E}$ buoy. Although the $80.5^{\circ} \mathrm{E}$ buoy has been in place since 2004 , no high-resolution data were available until 2008. Likewise, no high-resolution data were available from the $90^{\circ} \mathrm{E}$ buoy until 2004. Gaps in the surface flux record occur when either wind, air temperature, SST, RH, or a combination of these variables were missing. Since we are interested in intraseasonal timescales, linear interpolation was used between data gaps less than or equal to 10 days when doing analysis. After interpolation, the $80.5^{\circ} \mathrm{E}$ buoy has three continuous time periods333 days from August 8, 2008 to July 6, 2009, 213 days from August 27, 2009 to March 27, 2010, and 119 days from July 27, 2012 to November 22, 2012. The $90^{\circ} \mathrm{E}$ buoy also has three continuous periods -133 days from November 8, 2004 to March 20, 2005, 902 days from July 30, 2009 to January 17, 2012, and 220 days from May 1, 2012 to December 6, 2012 (Fig. 1). Since LHFLX is about an order of magnitude larger than SHFLX (black vs. grey lines in Fig. 1), our anal- ysis for the remainder of the paper focuses on LHFLX.

\section{$2.2 T R M M 3 B 42$}

TRMM 3B42 is a merged precipitation product providing 3-hour rainfall measurements at $0.25^{\circ} \times$ $0.25^{\circ}$ resolution, which we averaged to daily timescales at a $1^{\circ} \times 1^{\circ}$ resolution following AM08. The precipitation time series were then interpolated to each buoy point location. Data were downloaded from the Goddard Space Flight Center Global Precipitation Analysis website (http://precip.gsfc.nasa. gov/). Input to TRMM 3B42 includes passive low earth orbit microwave satellite data, geosynchronous earth orbit (GEO) infrared (IR) satellite data, TRMM Combined Instrument (TCI) estimates, the GPCP monthly rain gauge analysis, and the Climate Assessment and Monitoring System (CAMS) monthly rain gauge analysis (Huffman et al. 2007). We use version 7 of TRMM 3B42, which includes several updates from previous versions detailed online (Huffman and Bolvin 2014).

\subsection{Global MJO index}

The real time multivariate MJO (RMM) index, developed by Wheeler and Hendon (2004), classifies each day in the tropics as representing one of 
eight MJO phases. Each phase represents the general geographical location of deep convection associated with the MJO as it propagates eastward. The index is derived from the leading pair of empirical orthogonal functions (EOFs) of the combined fields of $15^{\circ} \mathrm{S}-15^{\circ} \mathrm{N}$ averaged outgoing longwave radiation (OLR) and 200- and 850-hPa zonal winds once the annual, interannual, and El Niño Southern Oscillation (ENSO) signals have been removed from each variable. Projection of daily averaged OLR and upper and lower zonal winds on to the leading EOF pair results in a principal component pair (PC), referred to as the RMM1 and RMM2 time series, that effectively describe the spatial and temporal evolution of the MJO. Because RMM1 leads RMM2 by about 10-15 days, eastward MJO propagation is indicated as counterclockwise rotation when plotted in standardized RMM1-RMM2 phase space (see Fig. 7, Wheeler and Hendon 2004).

\section{Intraseasonal LHFLX-precipitation relationship}

\subsection{Relationship of 20-100-day LHFLX and precipi- tation anomalies}

To address the primary question of this work - are surface fluxes sufficient to destabilize the atmospheric column on MJO timescales, Fig. 2 shows the scatterplot of TRMM precipitation anomalies (in energy units) versus LHFLX anomalies for the $80.5^{\circ} \mathrm{E}$ and $90^{\circ} \mathrm{E}$ buoys. By comparing the two variables in equivalent energy units, we evaluate if surface fluxes are an important source of column MSE compared to previously published rates at which convection discharges column MSE. Prior to plotting, each continuous time chunk of the LHFLX and precipitation time series for the $80.5^{\circ} \mathrm{E}$ and $90^{\circ} \mathrm{E}$ buoy were subject to a $20-100$ day non-recursive Lanczos bandpass filter with 60 weights. Only every fourth day is plotted, yet statistics are calculated using all available days. These plots are similar to Fig. 3 of AM08 and Fig. 8 of Maloney and Esbensen (2007), except here precipitation is plotted on the x-axis and LHFLX on the y-axis, which is a more relevant convention in the context of moisture mode theory (Raymond et al. 2009). Specifically, in both Maloney and Esbensen (2007) and AM08, the linear regressions were computed as

$$
b=\rho(x, y) \frac{\sigma_{x}}{\sigma_{y}}
$$

where $\rho$ is the correlation between $x$ and $y$, and $\sigma$ is the standard deviation for the subscripted variable, with the LHFLX time series as the $x$ variable and precipitation time series as the $y$ variable. In other words, LHFLX was used as the independent variable and precipitation as the dependent variable. In this study, the independent and dependent variables are been switched; precipitation is used as the independent variable (i.e., $x$ in Eq. 2) and LHFLX as the dependent variable (i.e., $y$ in Eq. 2), because we were interested in the magnitude of LHFLX at peak precipitation, which more directly assesses consequences for the destabilization of the MJO.

The black solid line is the linear best-fit line that minimizes the chi-square error statistic. The correlation and regression coefficients are labeled at the top left of each panel. Correlation coefficients are statistically significant at the $90 \%$ level for both buoys. Significance was determined following AM08 using a Student's $t$-test. Degrees of freedom (DOF) for the purpose of assessing the correlation coefficient significance were determined by dividing the number of days that went in to each plot by 40 , the approximate length of an MJO event.

The black bars on each plot indicate the $90 \%$ confidence intervals for the means of $200 \mathrm{~W} \mathrm{~m}^{-2}$ wide precipitation bins, where means are indicated by black dots. Bins are centered on $-300,-100,0,100$, and $300 \mathrm{~W} \mathrm{~m}^{-2}$, and confidence limits were computed using the $t$-statistic. DOFs for each $200 \mathrm{~W} \mathrm{~m}^{-2}$ bin were found by estimating the number of independent MJO events per bin. To do this, we made use of the average characteristics of the MJO as described by the RMM indices. Data in each bin were assigned RMM phases and ordered according to date. Consecutive days in each bin were assumed to belong to the same MJO event. Non-consecutive days belonged to the same MJO event if the time span between the data were below an allowablea "phase gap threshold." The phase gap threshold was defined as eight times the phase difference between the non-consecutive days. Eight represents the approximate number of days spent in each RMM phase (choosing five or ten changed the error bars very little). For example, at the $90^{\circ} \mathrm{E}$ buoy, May 2-3 and May 21-23, 2010 fall into the same LHFLX bin. May 2 and 3 are in RMM phase 2, while the May 21 and 23 are in phase 6 . Eight times the phase difference between the two sets of days means there may be up to 32 days separating the two sets of days for both sets to occur in the same MJO event. Given that there are 18 days between the two dates, it seems plausible that the days in between experienced phases 3-5. A check on days May 4-20 confirms those days did in fact experience phases 3-5. This method of determining DOFs is slightly stricter 

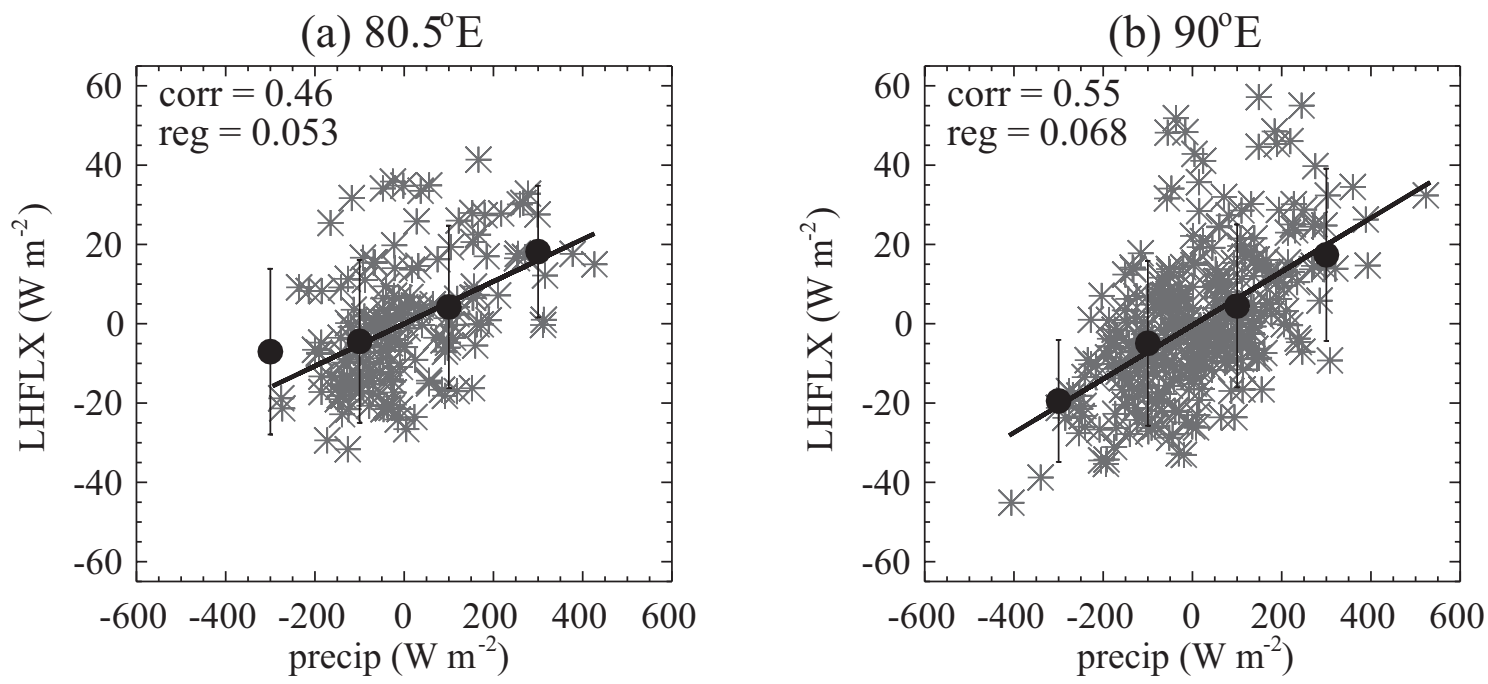

Fig. 2. Scatterplots of anomalous LHFLX vs. anomalous TRMM precipitation at the (a) $80.5^{\circ} \mathrm{E}$ and (b) $90^{\circ} \mathrm{E}$ buoy. Anomalies are relative to each continuous time chunk in Fig. 1. Asterisks represent one day in the data record, where only every fourth day has been plotted. The solid line is the linear best-fit line that minimizes the chi-squared error statistic. Black dots indicate the mean of $200 \mathrm{~W} \mathrm{~m}^{-2}$ wide LHFLX bins, while the error bars are the $90 \%$ confidence limit for each bin computed using the t-statistic. See text for explanation and example on how DOF for the best-fit line and for each LHFLX bin were calculated.

than Maloney and Esbensen (2007) and AM08 in which a 10-day or larger time span between non-consecutive days was essentially the requirement for counting independent MJO events.

At the $80.5^{\circ} \mathrm{E}$ buoy, regression coefficients indicate LHFLX anomalies are approximately $5 \%$ of TRMM precipitation anomalies (Fig. 2a). At the $90^{\circ} \mathrm{E}$ buoy, LHFLX anomalies are approximately $7 \%$ of TRMM precipitation anomalies, (Fig. 2b). The LHFLXTRMM precipitation relationships for the two Indian Ocean buoys are similar to what AM08 found using two west Pacific TOGA TAO buoys, and TRMM precipitation in that both regions show a positive relationship between precipitation and LHFLX. However, the ratio of LHFLX anomalies to precipitation anomalies associated with the Indian Ocean buoys are approximately a third as large as the ratio AM08 found (i.e., approximately $7 \%$ vs. $20 \%$ ). Ramifications of these various intraseasonal LHFLX to precipitation ratios are discussed in Section 6.

\subsection{Coherence and phase relationship between precipitation and LHFLX}

To further quantify the relationship between intraseasonal LHFLX and precipitation, we examine the coherence and phase relationship between the paired time series. Figure 3 shows the coherence squared between precipitation and LHFLX computed using time series for each buoy location. The cross spectrum and power spectrum were calculated for 100-day long segments and then averaged together to estimate the coherence squared and phase relationship over the entire time series. The $80.5^{\circ} \mathrm{E}$ buoy has six 100 -day segments, while the $90^{\circ} \mathrm{E}$ buoy has twelve (Fig. 1). As a consistency check, coherence was also calculated for the longest continuous timespan at each buoy and then subject to re-binning of adjacent periods. Both methods gave similar results, but we show coherence computed via segments as that method maximized the usable portion of each time series. The dotted line indicates the $95 \%$ confidence level following Biltoft and Pardyjak's (2009) coherence significance test (their Eq. 3). DOF were estimated as two times the number of 100-day segments.

At the $90^{\circ} \mathrm{E}$ buoy, a broad peak in coherence exists between LHFLX and TRMM precipitation spanning intraseasonal timescales, with maximum coherence squared near 0.7 in the intraseasonal band (Fig. 3a). The average coherence between the intraseasonal band (i.e., 20-100 days) is near 0.4, which is above the statistically significant line. At intraseasonal timescales, precipitation leads LHFLX by approximately a day at shorter intraseasonal periods to several days at longer intraseasonal periods (Fig. 
(a) $90^{\circ} \mathrm{E}$

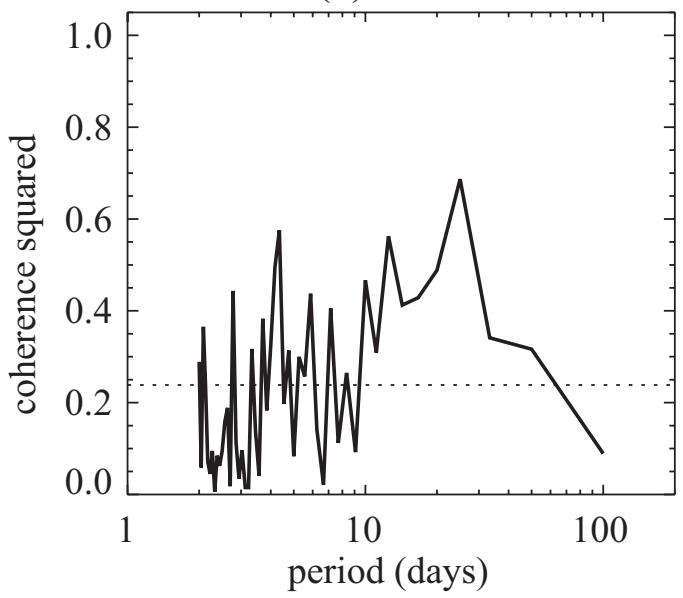

(c) $80.5^{\circ} \mathrm{E}$

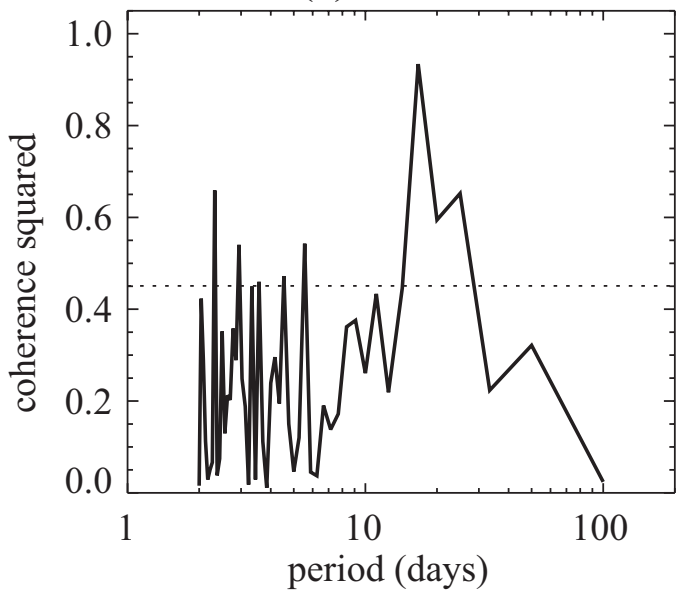

(b) $90^{\circ} \mathrm{E}$

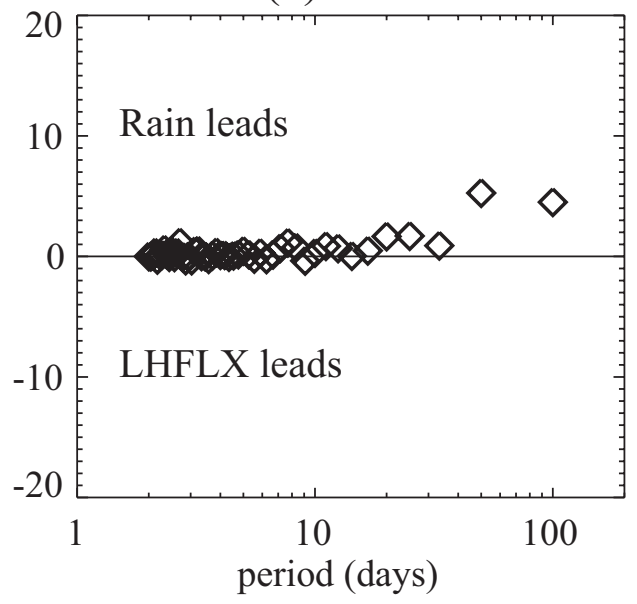

(d) $80.5^{\circ} \mathrm{E}$

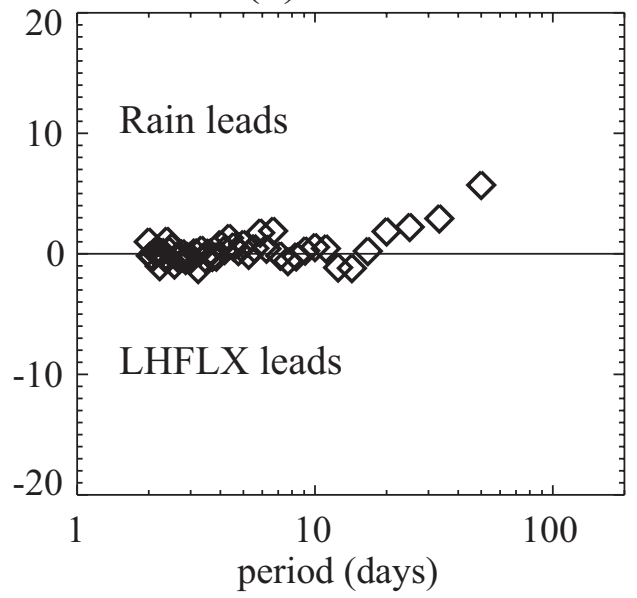

Fig. 3. Coherence squared between LHFLX and TRMM at the (a) $90^{\circ} \mathrm{E}$ buoy and (c) $80.5^{\circ} \mathrm{E}$ buoy. (b) Phase relationship between LHFLX and TRMM at the $90^{\circ} \mathrm{E}$ buoy. (d) Same as (b), except for the $80.5^{\circ} \mathrm{E}$ buoy. See text for details on how coherence was calculated. The dashed lines in (a) and (c) represent the $95 \%$ significance level following the significance formula in Biltof and Pardyjak's (2009).

3b). Results are similar at the $80.5^{\circ} \mathrm{E}$ buoy, although the significant peak in coherence occurs in a narrower period range (Figs. 3c, d). Implications for the precipitation-LHFLX lead-lag relationship are discussed in Section 6.

\subsection{Relationship of LHFLX and precipitation using global MJO phases}

The precipitation-LHFLX relationship is now considered for the RMM (Wheeler and Hendon 2004) global MJO index (discussed in Section 2.3). Each day in the LHFLX and precipitation time series was assigned an RMM phase. Only days that had an RMM amplitude greater than or equal to one were retained for analysis, as this is a common amplitude threshold for classifying RMM MJO events (e.g., Wheeler and Hendon 2004). The average LHFLX and precipitation value was then computed for each phase. Phase anomalies were then calculated as deviations from the all-phase mean of each respective variable.

Figure 4 presents the precipitation versus LHFLX phase anomalies for the $80.5^{\circ} \mathrm{E}$ (panel a) and $90^{\circ} \mathrm{E}$ (panel b) buoys for RMM phases 1-8. Large black numbers in Fig. 4 indicate phase anomalies where the original two time series were subject to a 20-100-day Lanczos filter, whereas anomalies indicated by small 
(a) $80.5^{\circ} \mathrm{E}$

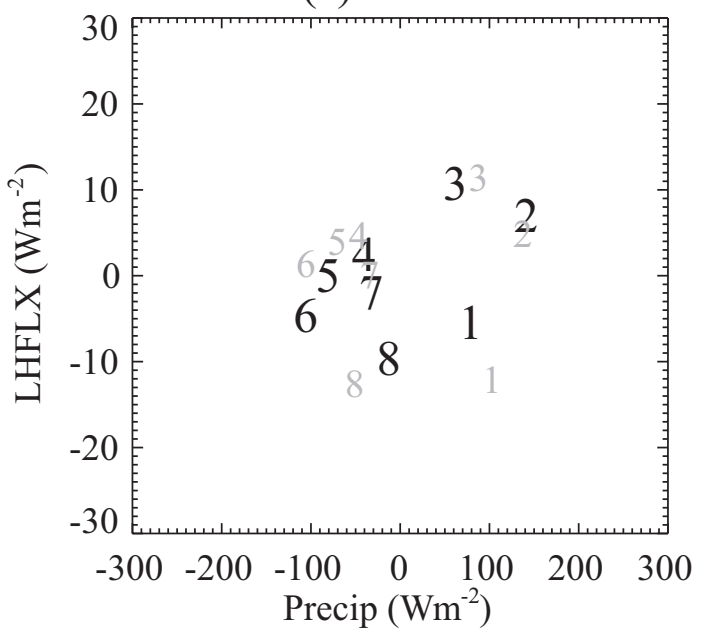

(b) $90^{\circ} \mathrm{E}$

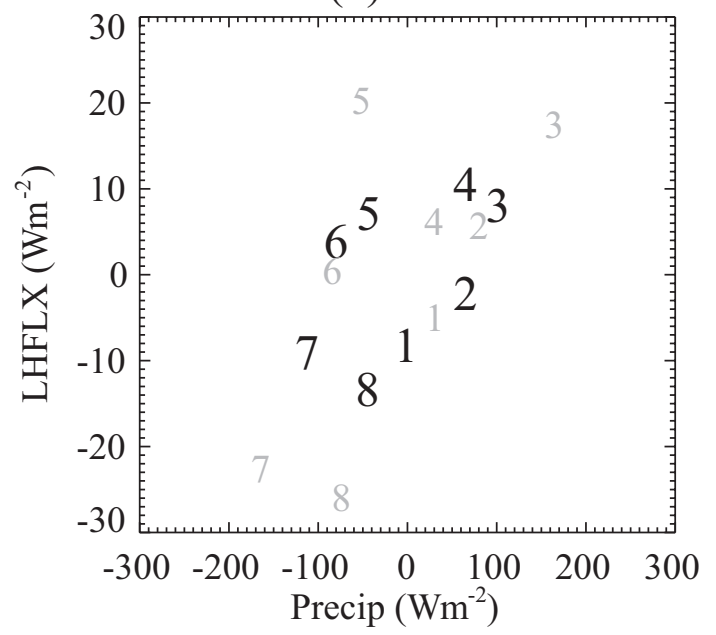

Fig. 4. LHFLX vs. TRMM precipitation anomalies for RMM phase at the (a) $80.5^{\circ} \mathrm{E}$ buoy and (b) $90^{\circ} \mathrm{E}$ buoy. Phase anomalies are calculated as deviations from all the phases (i.e., phases 1-8) mean. Grey small numbers are phases using unfiltered time series, while black large numbers are phases using 20-100-day Lanczos filtered time series.

grey numbers were computed with the raw, unfiltered LHFLX and precipitation time series. The filtered time series provides clearer results but does not qualitatively alter the interpretation of the results, as discussed below. As before, precipitation values have been converted to energy units to be synonymous with LHFLX units.

Using the filtered time series, both buoys show an elliptical counterclockwise progression of precipitation-LHFLX anomalies with the major axis of the ellipses, where the diagonal one unit of LHFLX to ten units of precipitation line would be. The plots indicate that precipitation and LHFLX have a lead-lag relationship, with precipitation leading LHFLX anomalies by about one phase (or 5-10 days). For example, for filtered and non-filtered RMM phases at $80.5^{\circ} \mathrm{E}$, precipitation anomalies maximize during phase 2, while LHFLX anomalies peak one phase later during phase 3 (Fig. 4).

Focusing on the results from the filtered time series, LHFLX anomalies are approximately $5 \%$ and $8 \%$ of precipitation anomalies at the time of peak precipitation amplitude for the $80.5^{\circ} \mathrm{E}$ and $90^{\circ} \mathrm{E}$ buoy, respectively (Fig. 4). These LHFLX to precipitation ratios are similar to the relationship between precipitation and LHFLX in Fig. 2 where intraseasonally filtered time series were compared. The elliptical shape, though, indicates that the ratio of LHFLX anomalies to precipitation anomalies changes throughout an MJO cycle. Only if phase anomalies fell along the $x-y$ diagonal would LHFLX consistently be approximately $10 \%$ of precipitation anomalies. However, one could argue that for assessing the ability of fluxes to destabilize the atmospheric column and help maintain the MJO active phase, we are most concerned with the strength of LHFLX anomalies at the time of peak precipitation.

There are slight phase variations in LHFLX-precipitation anomalies between the two buoys. Precipitation and LHFLX anomalies are largest during phases 3 and 4 , respectively, at the $90^{\circ} \mathrm{E}$ buoy compared to phases 2 and 3 at the $80.5^{\circ} \mathrm{E}$ buoy. Given that the phase numbers represent the approximate physical location of eastward propagating deep convection associated with the MJO, buoys farther east should, by design, have maximum precipitation values at later phases.

\section{Controls of intraseasonal LHFLX}

\subsection{Sensitivity of LHFLX to wind vs. air-sea humidity differences}

To quantify the importance of wind speed relative to thermodynamic variability in controlling intraseasonal LHFLX variations, sensitivity tests were conducted where LHFLX was recomputed twice using selective smoothing to the input time series to the COARE flux algorithm. In one re-computation, the high-resolution wind speed was smoothed using 
(a) $80.5^{\circ} \mathrm{E}$ smoothed thermo

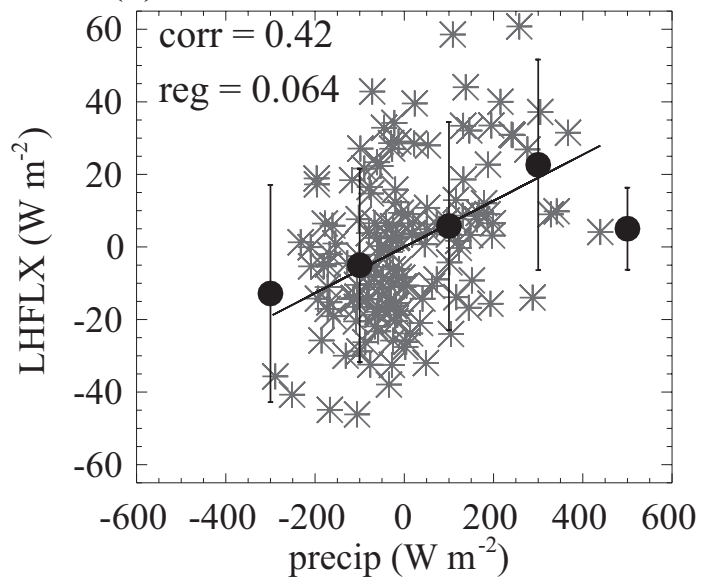

(c) $80.5^{\circ} \mathrm{E}$ smoothed wind

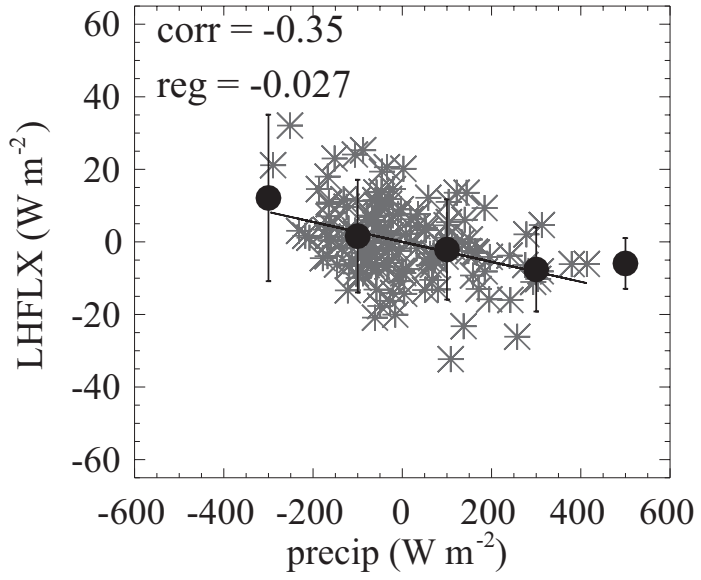

(b) $90^{\circ} \mathrm{E}$ smoothed thermo

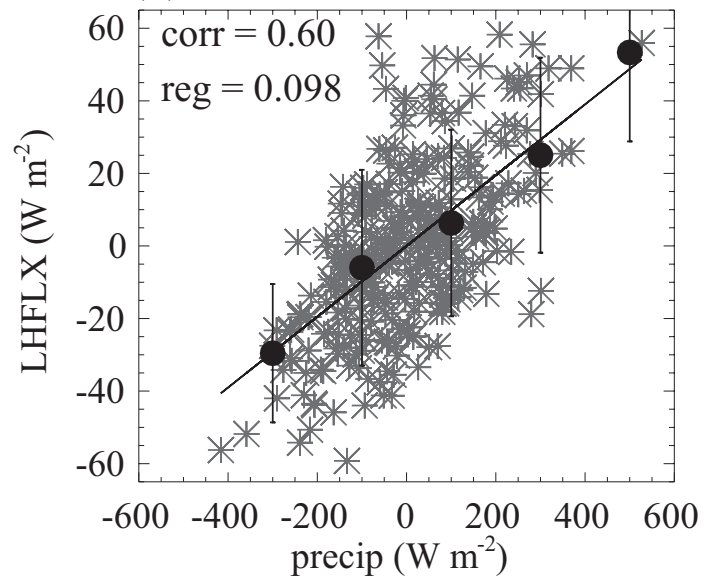

(d) $90^{\circ} \mathrm{E}$ smoothed wind

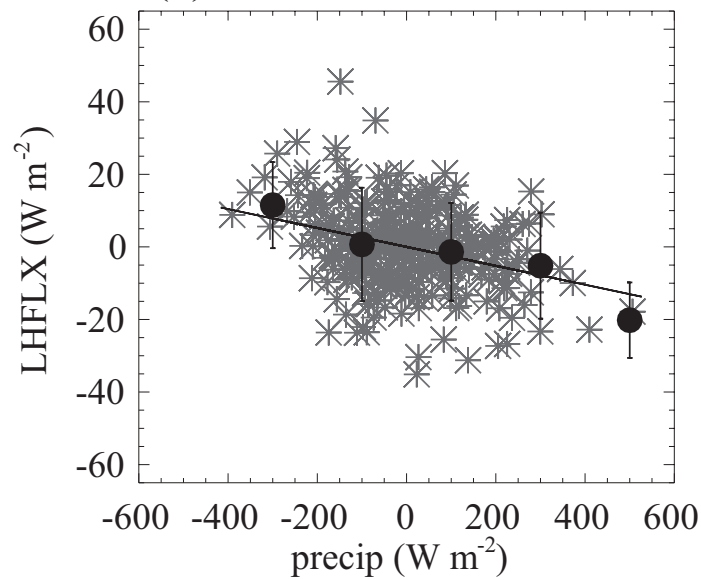

Fig. 5. TRMM precipitation-LHFLX relationship when LHFLX is computed using smoothed thermodynamics (top) and smoothed winds (bottom) for $80.5^{\circ} \mathrm{E}$ (left) and $90^{\circ} \mathrm{E}$ (right). Asterisks, dots, and lines have the same meaning as in Fig. 2.

a 50-day running average while the thermodynamic (i.e., SST, RH, and air $T$ ) time series remained the same. A 50-day running mean effectively removes MJO-timescale wind variability from the wind field. In the other computation, the thermodynamic time series were smoothed while the wind speed was not smoothed.

The intraseasonal LHFLX-precipitation anomaly relationship remains qualitatively similar to the full LHFLX field (i.e., positively correlated) at each buoy when LHFLX was computed with the intraseasonally smoothed thermodynamic variables and the original (i.e., unsmoothed) wind speed (Figs. 5a, b). LHFLX and TRMM anomalies are still significantly correlated at the $90 \%$ level. Regression coefficients increase by approximately $40 \%$ and $60 \%$ between LHFLX and the TRMM rainfall, such that LHFLX anomalies are now approximately $7.5 \%$ and $11 \%$ of precipitation anomalies for the $80.5^{\circ} \mathrm{E}$ and $90^{\circ} \mathrm{E}$ buoys, respectively.

When intraseasonally smoothed winds are used to compute LHFLX, the LHFLX-precipitation anomaly relationship on intraseasonal timescales fundamentally changes (Figs. 5c, d). Correlation and regression coefficients are now negative at both buoys. In this sensitivity run, only the correlation coefficient at the $90^{\circ} \mathrm{E}$ buoy is statistically significant at the $90 \%$ level. We note that when only a 20-day running average was used to smooth the wind time series, the relationship between intraseasonally filtered LHFLX and precipi- 
tation remained similar to when the two unsmoothed time series were used to calculate LHFLX (i.e., similar to Fig. 2).

Further sensitivity testing was done by re-evaluating the coherence and phase relationship of precipitation and LHFLX for LHFLX computed using either the smoothed thermodynamics or smoothed wind speed time series. When LHFLX was computed using smoothed thermodynamics, the coherence and phase relationship between precipitation and LHFLX remained characteristically the same as Fig. 3 (not shown). The coherence plot using the smoothed high-resolution wind speed was much noisier and coherence was generally not statistically significant (not shown). However, the phase relationship between LHFLX and precipitation at intraseasonal timescales changed substantially when smoothed winds were used to compute LHFLX (not shown). The thermodynamic component of LHFLX increasingly led precipitation from the short to long end of the intraseasonal period range (i.e., 20-100 days). These results are consistent with Figs. 5c, d that showed a negative correlation between filtered LHFLX and precipitation when LHFLX was computed using the smoothed wind speed time series, but showed a positive relationship when smoothed thermodynamics were used to compute LHFLX (Figs. 5a, b).

Physically, the computation of LHFLX with complementary smoothed time series indicates that intraseasonal LHFLX anomalies are primarily wind driven. That is, the positive relationship between intraseasonal LHFLX anomalies and precipitation anomalies in Fig. 2 and the strong coherence of the two variables over intraseasonal timescales (i.e., Fig. 3) is primarily explained by wind variability. Other studies have also found LHFLX anomalies to be primarily wind driven (Jones and Weare 1996; Maloney and Esbensen 2007; AM08; Grodsky et al. 2009; Yokoi et al. 2014). Thermodynamic variability, on the other hand, largely opposes or damps the positive relationship between intraseasonal LHFLX anomalies and precipitation anomalies (i.e., Figs. 5c, $d$ and the change in phase relationship between the two variables when smoothed wind speeds were used to compute LHFLXs, not shown). Accordingly, examination of the range along the LHFLX anomaly axis at the top and bottom panels of Fig. 5 vs. Fig. 2 indicates that thermodynamic variability decreases the spread of LHFLX anomalies compared to the spread that would exist if wind variability were acting alone. The change in standard deviation among various LHFLX computations verifies the visual differences seen between Figs. 2 and 5. The standard deviation of LHFLX increases from 15.5 to $20.7 \mathrm{~W} \mathrm{~m}^{-2}$ and from 17.9 to $23.7 \mathrm{~W} \mathrm{~m}^{-2}$ at the $80.5^{\circ} \mathrm{E}$ and $90^{\circ} \mathrm{E}$ buoys, respectively, when the smoothed thermodynamic fields are used to compute LHFLX. Conversely, the standard deviation of LHFLX decreases from 15.5 to $10.6 \mathrm{~W} \mathrm{~m}^{-2}$ and from 17.9 to $11.5 \mathrm{~W} \mathrm{~m}^{-2}$ at the $80.5^{\circ} \mathrm{E}$ and $90^{\circ} \mathrm{E}$ buoys, respectively, when the smoothed wind field is used to compute LHFLX.

\subsection{Linearization of the LHFLX formula across global MJO indices}

The relative importance of wind speed variability vs. thermodynamic variability as a function of global MJO phase is achieved by linearization of the LHFLX bulk formula. Through Reynolds decomposition, the following expression is obtained:

$$
L H^{\prime}=\rho L C_{H}\left(v^{\prime} \overline{\Delta q}+\bar{v} \Delta q^{\prime}+\left(v^{\prime} \Delta q^{\prime}\right)^{\prime}\right),
$$

where $\rho$ is the density of near-surface air, $L$ is the latent heat of vaporization, and $C_{H}$ is the exchange coefficient, $v$ is daily averaged buoy wind speed, and $\Delta q$ is the difference between daily averaged surface saturation specific humidity and daily averaged boundary layer specific humidity. Overbars represent averages over an entire MJO cycle (i.e., RMM phases 1-8), while primes represent the deviation of individual phase averages from the all-phase mean. $\rho L C_{H}$ was prescribed as a constant such that the average ratio of actual LHFLX anomalies to linearized LHFLX anomalies across all global phases is equal to one. A similar decomposition was conducted by Maloney and Esbensen (2005).

Figure 6 presents each component of Eq. (3) (red and blue lines), except for the third term inside the brackets that is negligible, along with LHFLX anomalies calculated from the COARE algorithm (black line) across RMM phases for the $80.5^{\circ} \mathrm{E}$ buoy (panel a) and the $90^{\circ} \mathrm{E}$ buoy (panel b). Note that LHFLX computed using the COARE flux algorithm and precipitation anomalies are the same values as those shown in Fig. 4 using the unfiltered time series (small grey numbers). The dashed line in each panel is the sum of the first two terms inside the brackets of Eq. 3 and shows how well the linear approximation matches the COARE algorithm. At both buoys, the component of the linearized LHFLX anomalies due to wind speed variability (i.e., first term inside brackets of Eq. 3 and red lines) explains nearly all the variability in LHFLX anomalies. The component due to air-sea humidity difference variability (i.e., 
(a) $80.5^{\circ} \mathrm{E}$

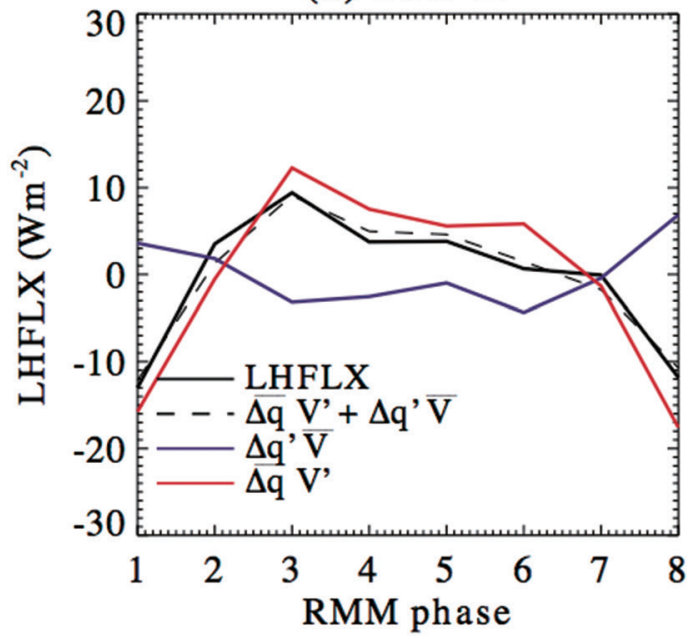

(b) $90^{\circ} \mathrm{E}$

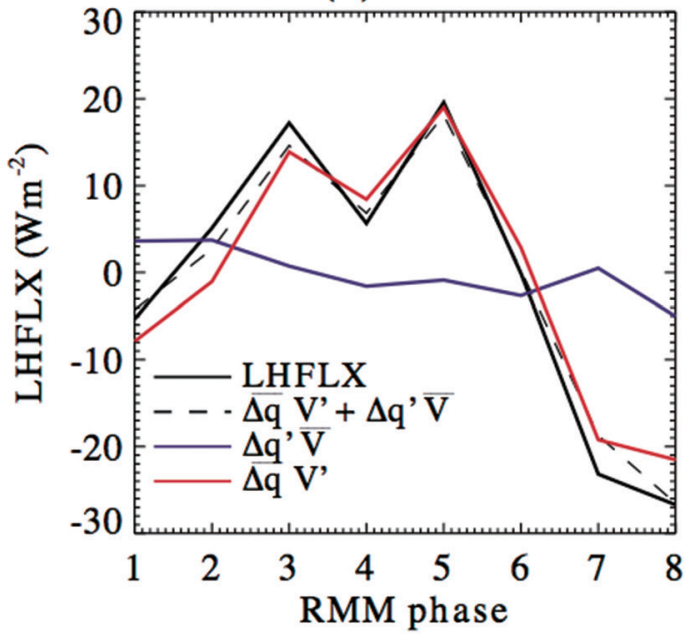

Fig. 6. Composite LHFLX anomalies and linearized LHFLX terms for RMM MJO phases at the (a) $80.5^{\circ} \mathrm{E}$ and (b) $90^{\circ} \mathrm{E}$ buoy. Bar represents the average over an entire MJO cycle (i.e., all 8 RMM phases), while primes represent intraseasonal variations. See text for more details.

second term inside brackets of Eq. 3 and blue lines) is generally out of phase with and smaller than the wind speed variability term and total LHFLX anomalies. Irrespective of MJO phase, air-sea humidity differences act mostly to reduce LHFLX anomalies, though the percentage reduction is not consistent across phases and in a few instances even enhances LHFLX anomalies. For example, during RMM phase 6 at the $90^{\circ} \mathrm{E}$ buoy, the two terms nearly cancel each other-the first term (red line) is $2.9 \mathrm{~W} \mathrm{~m}^{-2}$, while the second term (blue line) is $-2.6 \mathrm{~W} \mathrm{~m}^{-2}$. In phase 7 , however, air-sea humidity differences reduce total LHFLX anomalies by only $2.5 \%$. Further, in phase 8 , both terms of Eq. (3) are negative; hence the air-sea humidity differences actually enhance total LHFLX anomalies. Shinoda et al. (1998) also showed that the reduction in LHFLX anomalies via air-sea humidity differences is not consistent across MJO phases (their Fig. 12), though this conclusion was not explicitly stated in their paper.

These results from the linearization of the LHFLX formula are consistent with the sensitivity experiments shown in Fig. 5 where the correlation between LHFLX and precipitation was explained primarily via wind speed variations, while thermodynamic variations damped or opposed the positive correlations.

\subsection{Importance of mesoscale variability to the MJO}

The importance of mesoscale wind variability to
LHFLX variability associated with the MJO is now evaluated in light of the large body of literature that has highlighted the importance of mesoscale convection to tropical dynamics (e.g., Esbensen and $\mathrm{McPh}-$ aden 1996; Houze 2004; Mapes et al. 2006; Del Genio 2012) and specifically the MJO (e.g., Moncrieff 2004; Riley et al. 2011). We only test one small piece of the possible mesoscale influence on tropical dynamics, in particular, the mesoscale effects on intraseasonal surface flux variability. Following Maloney and Esbensen (2007), the effect of mesoscale variability is minimized by computing LHFLX from wind speed reconstructed from daily averaged wind vectors. Figure 7 presents the precipitation-LHFLX relationship at each buoy for LHFLX calculated using daily averaged vector winds. For the $80.5^{\circ} \mathrm{E}$ buoy, regression and correlation coefficients are no longer significantly different than zero at the $90 \%$ level. Similar to Maloney and Esbensen (2007), the precipitation-LHFLX relationship resembles the relationship using LHFLX computed from the full wind field, (cf., Figs. 2, 4a, b) but with decreased regression and correlation coefficients. Regression coefficients decrease by approximately $22 \%$ and $12 \%$ for the $80.5^{\circ} \mathrm{E}$ and $90^{\circ} \mathrm{E}$ buoy, respectively. The reduction in regression and correlation coefficients indicates that mesoscale gustiness contributes to the precipitationLHFLX relationship, but does not fully explain the relationship. 
(a) $80.5^{\circ} \mathrm{E}$ daily vec

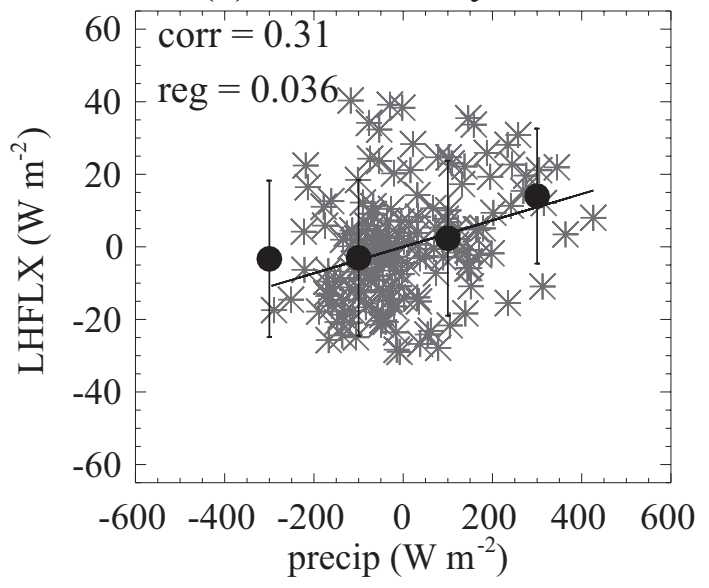

(c) $80.5^{\circ}$ E 3-day vec

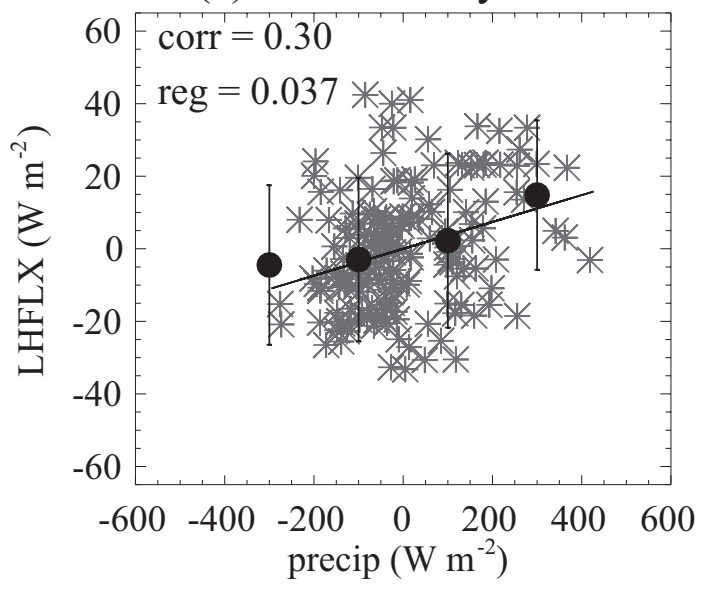

(b) $90^{\circ} \mathrm{E}$ daily vec

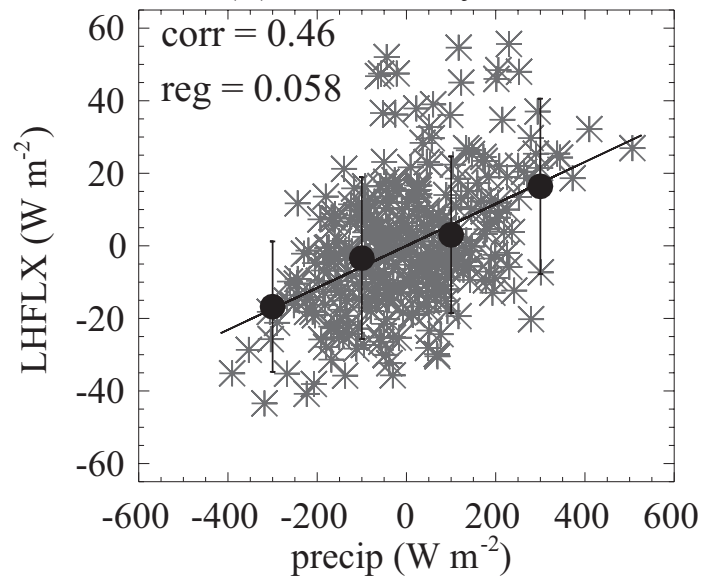

(d) $90^{\circ}$ E 3-day vec

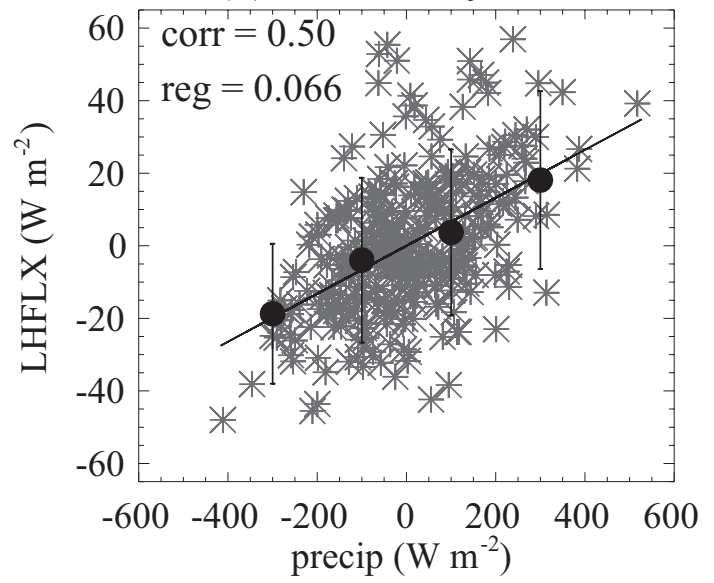

Fig. 7. Scatterplots of LHFLX anomalies and TRMM precipitation anomalies when LHFLX was computed using wind speed calculated from $(\mathrm{a}, \mathrm{b})$ daily averaged wind vectors at the $80.5^{\circ} \mathrm{E}$ and $90^{\circ} \mathrm{E}$ buoy, respectively. (c, d) Same as (a) and (b), but using 3-day-averaged wind vectors to compute LHFLX anomalies. Asterisks, lines, and dots have the same meaning as in Fig. 2.

Wind speed was also constructed from three day averaged wind vectors and used to determine LHFLX anomalies (Figs. 7 c, d). The three-day average (effectively a six-day low pass filter) eliminates much of the synoptic-timescale wind variability, which was shown by Maloney and Esbensen (2007) to contribute strongly to the intraseasonal wind speed signal in the east Pacific. The LHFLX-precipitation correlation remains similar to the original LHFLX-precipitation scatter plots (Fig. 2) and those derived from LHFLX calculated from daily mean vector winds (Figs. 7a, b). At the $80.5^{\circ} \mathrm{E}$ buoy, regression and correlation coefficients are similar compared to when daily vector winds were used, while the coefficients increase slightly at the $90^{\circ} \mathrm{E}$ buoy. The phase relationship between precipitation and LHFLX remained the same when mesoscale and synoptic scale variability were minimized (not shown). This is similar to what Araligidad (2007) found in the west Pacific using TAO buoys and suggests that synoptic scale variability does not contribute much to intraseasonal LHFLX anomalies.

\section{Robustness of conclusions to different datasets and MJO index}

As a check on the robustness of our results using TRMM precipitation measurements, all analysis was repeated using rainfall collected from the buoys and 
Table 1. Regression and correlation coefficients between intraseasonal LHFLX anomalies at the indicated buoy and intraseasonal precipitation from the indicated source. Regression coefficients are shown in percentage LHFLX to precipitation given that the variables are compared in equivalent energy units. Correlation coefficients are in parentheses. Correlation coefficients are statistically significant at the $90 \%$ level, except at the $80.5^{\circ} \mathrm{E}$ buoy when buoy precipitation is used.

\begin{tabular}{|c|c|c|c|}
\hline & TRMM & GPCP & Buoy \\
\hline \multirow{2}{*}{$\mathbf{8 0 . 5}^{\circ} \mathbf{E}$} & $\begin{array}{c}5.3 \% \\
(0.53)\end{array}$ & $\begin{array}{l}5.5 \% \\
(0.47)\end{array}$ & $\begin{array}{l}3.8 \% \\
(0.30)\end{array}$ \\
\hline \multirow{2}{*}{$\mathbf{9 0}^{\circ} \mathbf{E}$} & $\begin{array}{c}6.8 \% \\
(0.55)\end{array}$ & $\begin{array}{l}8.2 \% \\
(0.61)\end{array}$ & $\begin{array}{l}5.5 \% \\
(0.37)\end{array}$ \\
\hline
\end{tabular}

from the Global Precipitation Climatology Project (GPCP). For GPCP, we used version 1.2 of the $1^{\circ} \times$ $1^{\circ}$ daily combination product downloaded from http:// precip.gsfc.nasa.gov/. Similar to the TRMM results, GPCP and buoy rainfall measurements at both buoy locations are positively correlated with LHFLX anomalies (Table 1). Only the correlation coefficient between buoy rainfall and LHFLX at the $80.5^{\circ} \mathrm{E}$ buoy is not statistically different from zero at the $90 \%$ level. At the $80.5^{\circ} \mathrm{E}$ buoy, the regression coefficients between LHFLX and GPCP are similar to the TRMM results, while LHFLX anomalies are a slightly smaller percentage of buoy precipitation anomalies (Table 1). At the $90^{\circ} \mathrm{E}$ buoy, LHFLX anomalies are a slightly larger fraction of GPCP anomalies, while they are a slightly smaller fraction of buoy anomalies compared to TRMM (Table 1). The difference in the relationship between LHFLX anomalies and buoy precipitation anomalies versus TRMM and GPCP anomalies is perhaps not surprising given that the buoy is a single point measurement and TRMM and GPCP are area-averaged values before interpolating to the buoy point location.

Robustness of the RMM results were also examined using the GPCP and buoy rainfall, as well as an alternate global MJO index, the OLR MJO index (OMI) developed by Kiladis et al. (2014). Their index differs from RMM in that MJO phases are based solely on convection (i.e., OLR). Figures like Figs. 4 and 6 , but using GPCP and buoy rainfall, as well as OMI phases, showed qualitatively similar results to the analysis using RMM phases (Table 2). At the $80.5^{\circ} \mathrm{E}$ buoy, during peak OMI rainfall, LHFLX anomalies are a larger percentage of precipitation anomalies compared to peak RMM rainfall. Interest-
Table 2. Ratio of LHFLX anomalies to indicated precipitation anomalies for each buoy during the peak RMM and OMI phase of precipitation. LHFLX and precipitation are compared in equivalent energy units and ratios are given in percent. Values in parentheses are for OMI phases. At the $80.5^{\circ} \mathrm{E}$ buoy, the peak RMM precipitation occurs in phase 2 for all rain products, while peak OMI precipitation occurs in phase 3 . At the $90^{\circ} \mathrm{E}$ buoy, all rainfall products have peak precipitation in RMM and OMI phase 3.

\begin{tabular}{|c|c|c|c|}
\hline & TRMM & GPCP & Buoy \\
\hline \multirow{2}{*}{$\mathbf{8 0 . 5}^{\circ} \mathbf{E}$} & $\begin{array}{c}5.0 \% \\
(10.0 \%)\end{array}$ & $\begin{array}{c}6.0 \% \\
(8.7 \%)\end{array}$ & $\begin{array}{c}6.7 \% \\
(12.6 \%)\end{array}$ \\
\hline \multirow{2}{*}{$\mathbf{9 0}^{\circ} \mathbf{E}$} & $\begin{array}{c}7.9 \% \\
(5.9 \%)\end{array}$ & $\begin{array}{c}7.1 \% \\
(5.7 \%)\end{array}$ & $\begin{array}{c}16.4 \% \\
(10.7 \%)\end{array}$ \\
\hline
\end{tabular}

ingly, the opposite is true at the $90^{\circ} \mathrm{E}$ buoy; during peak OMI rainfall LHFLX are a smaller percentage of precipitation anomalies compared to peak RMM rainfall. Subtle difference in the overall progression of RMM vs. OMI anomalies include: 1) OMI had more variability in LHFLX and precipitation through an MJO cycle (i.e., the ellipse was larger); 2) OMI phases were shifted slightly clockwise relative to RMM phases; and 3) both maximum LHFLX and precipitation anomalies occurred in phase 3 at the $80.5^{\circ} \mathrm{E}$ buoy, suggesting no lead-lag relationship between the two variables. Differences are subtle enough to conclude that the relationship between precipitation and LHFLX associated with MJO variability (at these two buoy locations) is independent of whether the MJO is defined by convection alone or in conjunction with wind signals.

\section{Discussion}

Previous studies estimated that deep convection discharges column MSE by vertical advection at a rate of approximately $20 \%$ of precipitation in warm pool regions and approximately $14 \%$ over the Maritime Continent (Yu et al. 1998). Recent MSE analysis by Sobel et al. (2014) for the DYNAMO MJO events found a similar rate of MSE discharge by vertical advection during peak MJO activitybetween $10 \%$ and $20 \%$ of precipitation (their Figs. $8 \mathrm{a}, 9 \mathrm{a})$. Our regression analysis showed intraseasonal LHFLX anomalies to be between $4 \%$ and $8 \%$ of intraseasonal precipitation anomalies depending on buoy location (Fig. 2) and rainfall product (Table 1). The ratio of LHFLX to precipitation was similar between $5 \%$ and $16 \%$ for the two buoys during the most convectively active RMM or OMI phase of 
the MJO (Fig. 4, Table 2). These results suggests that LHFLX anomalies may be sufficient to destabilize the MJO in the west Pacific, as AM08 postulated, but may not be large enough, on their own, for MJO destabilization in the Indian Ocean, although they may still play a significant role. Radiation feedbacks may be important to complete the destabilization process (e.g., Andersen and Kuang 2012; Chikira 2014). In fact, Lin and Mapes (2004) found anomalous column-integrated cloud radiative heating to be $10 \%-15 \%$ of precipitation anomalies in the west Pacific. If a similar cloud radiative heating anomaly is observed in the Indian Ocean, LHFLX and cloud radiative feedbacks together could be enough to destabilize the MJO. Future studies will use CERES (i.e., Clouds and the Earth's Radiant Energy System) data to quantify radiative heating relative to precipitation over the Indian Ocean. The effects of horizontal advection also need to be considered, as anomalous advective drying shows a non-zero covariance with MJO convection (e.g., Kiranmayi and Maloney 2011; Kim et al. 2014; Chikira 2014).

The lead-lag relationship of LHFLX and precipitation shown in Figs. 3b, 3d and 4 is consistent with Shinoda et al. (1998), Jones et al. (1998), and Robertson and Roberts (2012), but contrary to Zhang (1996). Using the European Centre for Medium-Range Weather Forecasts (ECMWF) surface analysis to calculate LHFLX and outgoing longwave radiation (OLR) to approximate deep convection, Shinoda et al. (1998) found LHFLX to lag maximum convection by approximately three days over the western Pacific and Indian Ocean between $2.5^{\circ} \mathrm{S}$ and $7.5^{\circ} \mathrm{S}$ for the average of $10 \mathrm{MJO}$ events with an approximate cycle length of 50 days (their Figs. 9, 10). Jones et al. (1998) also used ECMWF reanalyses to estimate LHFLX and OLR as a deep convective proxy and found that over the west Pacific and Indian Ocean LHFLX anomalies maximize when westerly winds are strongest, approximately one to two pentads (5 day averages) after convection. Robertson and Roberts (2012) looked at tropical intraseasonal variability from both Modern-Era Retrospective analysis for Research and Applications (MERRA) reanalysis and observations from TRMM and the OAFlux dataset (i.e., objectively analyzed air-sea fluxes for the global ocean; Yu and Weller 2007) from 2000 to 2007 and found that LHFLX lagged precipitation in both. Zhang (1996), however, found that surface heat fluxes slightly lead precipitation in the 30-90 day frequency band. His paper looked at area-averaged surface fluxes over a subset of the TAO buoys in the west Pacific relative to high cloud cover (i.e., a proxy for deep precipitation) estimates from geostationary satellites. These differences could indicate that the relationship between surface fluxes and precipitation changes as the MJO moves eastward. Indeed, Zhang (2005) discussed four models on the phase relationship between MJO convection and surface fluxes as convection propagates eastward. Over the Indian Ocean, Model I depicts convection between westerlies to the west and easterlies to the east, while the Pacific Ocean resembles Model II more with convection and strong westerlies in phase (Zhang 2005, Fig 6). Alternatively, the use of different precipitation estimates and areal averaging may explain the differences as TRMM 3B42 estimates are arguably more accurate than geostationary satellites alone at identifying deep convection.

The dominance of wind speed to LHFLX variations was also found in Shinoda et al. (1998), Maloney and Esbensen (2005) and Araligidad and Maloney (2008). Maloney and Esbensen (2005), though, found the air-sea humidity difference term to have negligible impact on total LHFLX variations for their model simulations of the boreal summertime intraseasonal oscillation (ISO) over the east Pacific. Their model did not have an interactive ocean and only fixed SSTs, which may explain the irrelevance of air-sea humidity differences. They also noted an asymmetry in LHFLX anomalies between building vs. decaying ISO phases. Similar asymmetries are noticeable between phases 1 and 8 at the $90^{\circ} \mathrm{E}$ buoy, but are not apparent for the $80.5^{\circ} \mathrm{E}$ buoy (Fig. 6). Perhaps if the $80.5^{\circ} \mathrm{E}$ buoy had more data, an asymmetry would also appear. As such, firm conclusions cannot be made about the asymmetry of LHFLX anomalies in building vs. decaying phases of the MJO over the Indian Ocean.

Plots were also made for the $8^{\circ} \mathrm{S} 80.5^{\circ} \mathrm{E}$ buoy to see how the relationship of the precipitation-LHFLX relationship varies away from the equator. The $8^{\circ} \mathrm{S}$ $80.5^{\circ} \mathrm{E}$ buoy has a continuous time span of high-resolution data between August 22, 2008 and July 8, 2012. Scatterplots (similar to Fig. 2) reveal a weakly negative relationship between filtered precipitation and LHFLX anomalies (not shown). Only the correlation coefficient between buoy precipitation and LHFLX is statistically different from zero at the $90 \%$ confidence level. Contrasting the results from the $8^{\circ} \mathrm{S}$ buoy with its equatorial counterpart reveals that the relationship between precipitation and LHFLX is not consistent across latitudes. Rather, LHFLX anomalies may only be important for locally supporting MJO convection on or very close to the equator, and even there, the 
magnitude of the flux anomaly may not be sufficient in itself to destabilize the MJO. Phase relationship plots between intraseasonal precipitation and LHFLX show that the $8^{\circ} \mathrm{S}, 80.5^{\circ} \mathrm{E}$ buoy lays near a region where the lead-lag relationship between precipitation and LHFLX is not statistically significant and near a transition latitude where the relationship switches from precipitation leading LHFLX to LHFLX leading precipitation (Charlotte DeMott, personal correspondence 2014). The $8^{\circ} \mathrm{S}$ buoy is also where the mean surface zonal wind changes sign from westerlies near the equator to easterlies further south. Maloney and Esbensen (2007) showed a similar inconsistency between LHFLX and precipitation for some regions of the east Pacific as the two variables had a negative (albeit, not statistically significant) relationship at the $8^{\circ} \mathrm{N}, 110^{\circ} \mathrm{W}$ buoy where mean winds were easterlies, unlike mean westerlies further east.

That intraseasonal LHFLX anomalies lag intraseasonal precipitation anomalies on the order of days and are dominated by wind speed variability for the two equator based buoys lead us to view wind induced surface fluxes as mechanistically important for maintaining MJO convection in the Indian Ocean along the equator and helping set the convective envelope's eastward propagation speed. Deep convection associated with the MJO enhances surface wind speed, which lead to enhanced surface fluxes that increase BL MSE (Eq. 1). The excess MSE is exported from the column by divergent motions from ensuing deep convection. In terms of aiding the eastward propagation, Maloney (2009) and Kiranmayi and Maloney (2011) suggested that the fact that LHFLX is in phase or slightly lags precipitation effectively slows down MJO propagation, as the discharge of column MSE is retarded compared to if horizontal and vertical advection of MSE were acting alone. The idealized model of Sobel and Maloney (2012, 2013) suggested a similar effect of fluxes on propagation.

\section{Summary}

Observations from two RAMA buoys along the equator at $80.5^{\circ} \mathrm{E}$ and $90^{\circ} \mathrm{E}$ were used to calculate LHFLX anomalies on intraseasonal timescales. LHFLX anomalies were compared to intraseasonal TRMM precipitation anomalies to assess the importance of LHFLX for maintaining convection on intraseasonal timescales. Using intraseasonally filtered time series, we found intraseasonal LHFLX to be primarily wind driven and positively correlated with precipitation anomalies for both buoys with LHFLX anomalies approximately $4 \%$ and $8 \%$ of precipitation anomalies depending on buoy location and rainfall product (Fig. 2, Table 1). A similar relationship was shown during the most convectively active RMM phases, except at the $90^{\circ} \mathrm{E}$ buoy when buoy precipitation was used (Fig. 4, Table 2). The elliptical progression of the RMM phase anomalies, though, indicated that the ratio of precipitation of LHFLX anomalies is not consistent through a complete MJO cycle (Fig. 4). Maloney (2009) also showed that the relationship between surface fluxes and precipitation for NCAR CAM3 simulations varied through the lifecycle of the model MJO, though that finding was not explicitly stated, with LHFLX being approximately $20 \%$ of precipitation during maximum rainfall (his Fig. 7). Coherence analysis between 20-100-day filtered precipitation and LHFLX time series showed that LHFLX anomalies lag precipitation anomalies on the order of days in the intraseasonal band (Fig. 3). Similar results were found using MJO RMM phases.

The contribution of intraseasonal LHFLX anomalies to precipitation anomalies for these Indian Ocean buoys is lower than that of previous results derived from the Pacific. Results from Maloney and Esbensen (2007) but for buoys in the east Pacific along $95^{\circ} \mathrm{W}$, found LHFLX anomalies to be between $20 \%$ and $50 \%$ of precipitation anomalies. Likewise, AM08 found a LHFLX-precipitation relationship around $20 \%$ for two buoys in the west Pacific along $165^{\circ} \mathrm{E}$. If, however, LHFLX is retained as the independent variable (i.e., $x$ in Eq. 2) and precipitation the dependent variable (i.e., $y$ in Eq. 2), the fraction of LHFLX anomalies to precipitation anomalies for the two Indian Ocean buoys used here are similar to Maloney and Esbensen (2007) and AM08 at approximately 20 $\%$.

In the context of moisture mode theory that requires support from column moistening processes to maintain the moisture anomaly that supports MJO convection, LHFLX anomalies of a value of $4 \%-16 \%$ of precipitation-depending on analysis type (i.e., Table 1 vs. 2), buoy location, and precipitation product - are likely important contributors to MJO destabilization. Furthermore, the dominance of wind variability to LHFLX anomalies supports the notion that wind-induced surface fluxes are important to MJO convection in the Indian Ocean as previously noted by AM08 for the west Pacific and Maloney and Esbensen (2007) for the east Pacific.

Meso- and synoptic-scale wind variabilities have relatively modest contributions to intraseasonal LHFLXs. Back and Bretherton (2005) and Araligidad (2007) came to similar conclusions by using area-av- 
eraged QuikSCAT wind vectors to compute wind speed to minimize the effects of wind variations associated with mesoscale convective variability. Our results do not rule out the importance of mesoscale convection to MJO dynamics. Vertical momentum transport by mesoscale circulations, which is not addressed here, could be an important driver of MJO dynamics and the grid-scale vector wind (e.g., Moncrieff 2004).

Surface fluxes are only one source of column moisture. Careful diagnoses of other terms in the MSE budget is necessary to reveal how important surface fluxes are relative to other processes affecting the moisture tendency (e.g., vertical advection and radiative feedbacks). More work is needed with reanalysis products, sounding datasets, and high resolution models to determine more exactly the magnitude of MSE discharge associated with MJO convection over the extended record and the threshold that diabatic MSE sources need to meet to help destabilize the $\mathrm{MJO}$, if it is indeed a moisture mode.

Further analysis using QuikSCAT wind retrievals over the Indian Ocean would benefit this work, as QuikSCAT enables the relationship between wind speed and precipitation to be diagnosed over a wider area than the single buoy points used here (Back and Bretherton 2005; AM08). However, QuikSCAT would only allow the wind component of the LHFLX to be assessed. Longer continuous records of in-situ flux observations would also be beneficial for diagnosing wind-flux feedbacks on convection. Cloud resolving model (CRM) simulations are another avenue to further study the importance of wind-induced LHFLX to intraseasonal precipitation. Future work, by the authors and collaborators, will include CRM simulations of MJO variability to isolate the importance of wind-flux feedbacks at various scales (e.g., convective, meso-, synoptic scale) to the dynamics of the MJO. Sensitivity experiments will control the strength of wind-induced LHFLX feedbacks to convection, including complete denial of wind-flux feedbacks, to test results found here and in other previous studies. Results of the observational work presented here and future model work will be useful to the development of the Cyclone Global Navigation Satellite System (CYGNSS), which is scheduled to launch in 2016 with a mission to provide high temporal and spatial scale measurements of ocean surface wind.

\section{Acknowledgments}

Discussions with Charlotte DeMott concerning this work are greatly appreciated. Reviewer comments improved the clarity of this work. This work was supported by the NASA CYGNSS program under grant NNX13AQ50G and the Climate and LargeScale Dynamics Program of the National Science Foundation under Grant AGS-1025584. The statements, findings, conclusions, and recommendations do not necessarily reflect the views of NASA or NSF.

\section{References}

Andersen, J. A., and Z. Kuang, 2012: Moist static energy budget of MJO-like disturbances in the atmosphere of a zonally symmetric aquaplanet. J. Climate, 25, 2782-2804.

Araligidad, N. M., 2007: Buoy and satellite observations of wind induced surface heat exchange in the intraseasonal oscillation over west Pacific and Indian Ocean. M.S. Thesis, Oregon State University, 83 pp.

Araligidad, N. M., and E. D. Maloney, 2008: Winddriven latent heat flux and the intraseasonal oscillation. Geophys. Res. Lett., 35, L04815, doi:10.1029/2007GL032746.

Back, L. E., and C. S. Bretherton, 2005: The relationship between wind speed and precipitation in the Pacific ITCZ. J. Climate, 18, 4317-4328.

Barnes, H. C., and R. A. Houze Jr., 2013: The precipitating cloud population of the Madden-Julian Oscillation over the Indian and west Pacific Oceans. J. Geophys. Res. Atmos., 118, 6996-7023.

Benedict, J. J., and D. A. Randall, 2007: Observed characteristics of the MJO relative to maximum rainfall. $J$. Atmos. Sci, 64, 2332-2354.

Benedict, J. J., and D. A. Randall, 2009: Structure of the Madden-Julian oscillation in the superparameterized CAM. J. Atmos. Sci., 66, 3277-3296.

Biltoft, C. A., and E. R. Pardyjak, 2009: Spectral coherence and the statistical significance of turbulent flux computations. J. Atmos. Oceanic Technol., 26, 403-410.

Chikira, M., 2014: Eastward-propagating intraseasonal oscillation represented by Chikira-Sugiyama cumulus parameterization. Part II: Understanding moisture variation under weak temperature gradient balance. $J$. Atmos. Sci., 71, 615-639.

Del Genio, A. D., 2012: Representing the sensitivity of convective cloud systems to tropospheric humidity in general circulation models. Surv. Geophys., 33, 637-656.

DeMott, C. A., C. Stan, D. A. Randall, and M. D. Branson, 2014: Intraseasonal variability in coupled GCMs: The roles of ocean feedbacks and model physics. $J$. Climate, 27, 4970-4995.

Emanuel, K. A., 1987: An air-sea interaction-model of intraseasonal oscillations in the tropics. J. Atmos. Sci., 44, 2324-2340.

Esbensen, S. K., and M. J. McPhaden, 1996: Enhancement 
of tropical ocean evaporation and sensible heat flux by atmospheric mesoscale systems. J. Climate, 9, 2307-2325.

Fairall, C. W., E. F. Bradley, J. E. Hare, A. A. Grachev, and J. B. Edson, 2003: Bulk parameterization of air-sea fluxes: Updates and verification for the COARE algorithm. J. Climate, 16, 571-591.

Grabowski, W. W., 2003: MJO-like coherent structures: Sensitivity simulations using the cloud-resolving convection parameterization (CRCP). J. Atmos. Sci., 60, 847-864.

Grodsky, S. A., A. Bentamy, J. A. Carton, and R. T. Pinker, 2009: Intraseasonal latent heat flux based on satellite observations. J. Climate, 22, 4539-4556.

Hannah, W. M., and E. D. Maloney, 2011: The role of moisture-convection feedbacks in simulating the Madden-Julian oscillation. J. Climate, 24, 2754-2770.

Haertel, P., K. Straub, and A. Budsock, 2014: Transforming circumnavigating Kelvin waves that initiate and dissipate the Madden-Julian Oscillation. Quart. J. Roy. Meteor. Soc., doi:10.1002/qj.2461.

Houze, R. A., Jr., 2004: Mesoscale convective systems. Rev. Geophys., 42, RG4003, doi:10.1029/2004RG000150.

Huffman, G. J., and D. T. Bolvin, 2014: TRMM and other data precipitation data set documentation. NASA GSFC Rep., 42 pp. [Available at ftp://precip.gsfc. nasa.gov/pub/trmmdocs/3B42_3B43_doc.pdf.]

Huffman, G. J., R. F. Adler, D. T. Bolvin, G. Gu, E. J. Nelkin, K. P. Bowman, Y. Hong, E. F. Stocker, and D. B. Wolff, 2007: The TRMM multisatellite precipitation analysis (TMPA): Quasi-global, multiyear, combined-sensor precipitation estimates at fine scales. J. Hydrometeor, , 8, 38-55.

Johnson, R. H., and P. E. Ciesielski, 2013: Structure and properties of Madden-Julian oscillations deduced from DYNAMO sounding arrays. J. Atmos. Sci., 70, 3157-3179.

Jones, C., D. E. Waliser, and C. Gautier, 1998: The influence of the Madden-Julian oscillation on ocean surface heat fluxes and sea surface temperature. J. Climate, 11, 1057-1072.

Jones, C., and B. C. Weare, 1996: The role of low-level moisture convergence and ocean latent heat fluxes in the Madden and Julian oscillation: An observational analysis using ISCCP data and ECMWF analyses. $J$. Climate, 9, 3086-3104.

Kikuchi, K., and Y. N. Takayabu, 2003: Equatorial circumnavigation of moisture signal associated with the Madden-Julian Oscillation (MJO) during boreal winter. J. Meteor. Soc. Japan, 81, 851-869.

Kiladis, G. N., J. Dias, K. H. Straub, M. C. Wheeler, S. N. Tulich, K. Kikuchi, K. M. Weickmann, and M. J. Ventrice, 2014: A comparison of OLR and circulation-based indices for tracking the MJO. Mon. Wea. Rev., 142, 1697-1715.

Kiladis, G. N., K. H. Straub, and P. T. Haertel, 2005: Zonal and vertical structure of the Madden-Julian oscillation. J. Atmos. Sci., 62, 2790-2809.

Kiladis, G. N., M. C. Wheeler, P. T. Haertel, K. H. Straub, and P. E. Roundy, 2009: Convectively coupled equatorial waves. Rev. Geophys., 47, RG2003, doi:10.1029/2008RG000266.

Kim, D., K. Sperber, W. Stern, D. Waliser, I.-S. Kang, E. Maloney, W. Wang, K. Weickmann, J. Benedict, M. Khairoutdinov, M.-I. Lee, R. Neale, M. Suarez, K. Thayer-Calder, and G. Zhang, 2009: Application of MJO simulation diagnostics to climate models. $J$. Climate, 22, 6413-6436.

Kiranmayi, L., and E. D. Maloney, 2011: Intraseasonal moist static energy budget in reanalysis data. J. Geophs. Res. Atmos., 116, D21117, doi:10.1029/2011JD016031.

Knutson, T. R., and K. M. Weickmann, 1987: 30-60 day atmospheric oscillations: Composite life cycles of convection and circulation anomalies. Mon. Wea. Rev., 115, 1407-1436.

Lin, J. L., and B. E. Mapes, 2004: Radiation budget of the tropical intraseasonal oscillation. J. Atmos. Sci., 61, 2050-2062.

Lin, X., and R. H. Johnson, 1996: Kinematic and thermodynamic characteristics of the flow over the western Pacific warm pool during TOGA COARE. J. Atmos. Sci., 53, 695-715.

Madden, R. A., and P. R. Julian, 1972: Description of global-scale circulation cells in the tropics with a 40-50 day period. J. Atmos. Sci., 29, 1109-1123.

Maloney, E. D., 2009: The moist static energy budget of a composite tropical intraseasonal oscillation in a climate model. J. Climate, 22, 711-729.

Maloney, E. D., and S. K. Esbensen, 2003: The amplification of east Pacific Madden-Julian oscillation convection and wind anomalies during June-November. $J$. Climate, 16, 3482-3497.

Maloney, E. D., and A. H. Sobel, 2004: Surface fluxes and ocean coupling in the tropical intraseasonal oscillation. J. Climate, 17, 4368-4386.

Maloney, E. D., and S. K. Esbensen, 2005: A modeling study of summertime east Pacific wind-induced ocean-atmosphere exchange in the intraseasonal oscillation. J. Climate, 18, 568-584.

Maloney, E. D., and S. K. Esbensen, 2007: Satellite and buoy observations of boreal summer intraseasonal variability in the tropical northeast Pacific. Mon. Wea. Rev., 135, 3-19.

Maloney, E. D., A. H. Sobel, and W. M. Hannah, 2010: Intraseasonal variability in an aquaplanet general circulation model. J. Adv. Model. Earth Syst., 2, 24 pp.

Mapes, B., S. Tulich, J. Lin, and P. Zuidema, 2006: The mesoscale convection life cycle: Building block or prototype for large-scale tropical waves? Dyn. Atmos. Oceans, 42, 3-29. 
Matthews, A. J., 2008: Primary and successive events in the Madden-Julian Oscillation. Quart. J. Roy. Meteor. Soc., 134, 439-453.

McPhaden, M. J., G. Meyers, K. Ando, Y. Masumoto, V. S. N. Murty, M. Ravichandran, F. Syamsudin, J. Vialard, L. Yu, and W. Yu, 2009: RAMA The research moored array for African-Asian-Australian monsoon analysis and prediction. Bull. Amer. Meteor. Soc., 90, 459-480.

Moncrieff, M. W., 2004: Analytic representation of the large-scale organization of tropical convection. $J$. Atmos. Sci., 61, 1521-1538.

Morita, J., Y. N. Takayabu, S. Shige, and Y. Kodama, 2006: Analysis of rainfall characteristics of the Madden-Julian oscillation using TRMM satellite data. Dyn. Atmos. Oceans, 42, 107-126.

Moum, J. N., S. P. de Szoeke, W. D. Smyth, J. B. Edson, H. L. DeWitt, A. J. Moulin, E. J. Thompson, C. J. Zappa, S. A. Rutledge, R. H. Johnson, and C. W. Fairall, 2014: Air-sea interactions from westerly wind bursts during the November 2011 MJO in the Indian Ocean. Bull. Amer. Meteor. Soc., 95, 1185-1199.

Nakazawa, T., 1995: Intraseasonal oscillations during the TOGA-COARE IOP. J. Meteor. Soc. Japan, 73, 305-319.

Neelin, J. D., I. M. Held, and K. H. Cook, 1987: Evaporation-wind feedback and low-frequency variability in the tropical atmosphere. J. Atmos. Sci., 44, 23412348.

Powell, S. W., and R. A. Houze, Jr., 2013: The cloud population and onset of the Madden-Julian Oscillation over the Indian Ocean during DYNAMO-AMIE. $J$. Geophs. Res. Atmos., 118, 11979-11995.

Raymond, D. J., and Ž. Fuchs, 2007: Convectively coupled gravity and moisture modes in a simple atmospheric model. Tellus A, 59, 627-640.

Raymond, D. J., and Ž. Fuchs, 2009: Moisture Modes and the Madden-Julian oscillation. J. Climate, 22, 30313046.

Raymond, D. J., S. L. Sessions, A. H. Sobel, and Ž. Fuchs, 2009: The Mechanics of gross moist stability. J. $A d v$. Model. Earth Syst., 1, 20 pp.

Riley, E. M., B. E. Mapes, and S. N. Tulich, 2011: Clouds associated with the Madden-Julian oscillation: A new perspective from CloudSat. J. Atmos. Sci., 68, 30323051.

Robertson, F. R., and J. B. Roberts, 2012: Intraseasonal variability in MERRA Energy fluxes over the tropical oceans. J. Climate, 25, 5629-5647.

Salby, M. L., and H. H. Hendon, 1994: Intraseasonal behavior of clouds, temperature, and motion in the tropics. J. Atmos. Sci., 51, 2207-2224.

Serra, Y. L., P. A'hearn, H. P. Freitag, and M. J. McPhaden, 2001: ATLAS Self-Siphoning Rain Gauge Error Estimates. J. Atmos. Oceanic Technol., 18, 1989-2002.

Shinoda, T., H. H. Hendon, and J. Glick, 1998: Intraseasonal variability of surface fluxes and sea surface temperature in the tropical western Pacific and Indian Oceans. J. Climate, 11, 1685-1702.

Sobel, A. H., and C. S. Bretherton, 2000: Modeling tropical precipitation in a single column. J. Climate., 13, 4378-4392.

Sobel, A., and E. Maloney, 2012: An idealized semi-empirical framework for modeling the Madden-Julian oscillation. J. Atmos. Sci., 69, 1691-1705.

Sobel, A., and E. Maloney, 2013: Moisture modes and the eastward propagation of the MJO. J. Atmos. Sci., 70, 187-192.

Sobel, A. H., J. Nilsson, and L. M. Polvani, 2001: The weak temperature gradient approximation and balanced tropical moisture waves. J. Atmos. Sci., 58, 36503665.

Sobel, A. H., E. D. Maloney, G. Bellon, and D. M. Frierson, 2008: The role of surface heat fluxes in tropical intraseasonal oscillations. Nat. Geosci., 1, 653-657.

Sobel, A. H., E. D. Maloney, G. Bellon, and D. M. Frierson, 2010: Surface fluxes and tropical intraseasonal variability: A reassessment. J. Adv. Model. Earth Syst., 2, $27 \mathrm{pp}$.

Sobel, A., S. Wang, and D. Kim, 2014: Moist static energy budget of the MJO during DYNAMO. J. Atmos. Sci., 71, 4276-4291.

Sugiyama, M., 2009a: The moisture mode in the quasi-equilibrium tropical circulation model. Part I: Analysis based on the weak temperature gradient approximation. J. Atmos. Sci., 66, 1507-1523.

Sugiyama, M., 2009b: The moisture mode in the quasi-equilibrium tropical circulation model. Part II: Nonlinear behavior on an equatorial $\beta$ plane. J. Atmos. Sci., 66, 1525-1542.

Wheeler, M. C., and H. H. Hendon, 2004: An all-season real-time multivariate MJO index: Development of an index for monitoring and prediction. Mon. Wea. Rev., 132, 1917-1932.

$\mathrm{Xu}, \mathrm{W}$., and S. A. Rutledge, 2014: Convective characteristics of the Madden-Julian oscillation over the central Indian Ocean observed by shipborne radar during DYNAMO. J. Atmos. Sci., 71, 2859-2877.

Yasunaga, K., and B. Mapes, 2012a: Differences between more divergent and more rotational types of convectively coupled equatorial waves. Part I: Space-time spectral analyses. J. Atmos. Sci., 69, 3-16.

Yasunaga, K., and B. Mapes, 2012b: Differences between more divergent and more rotational types of convectively coupled equatorial waves. Part II: Composite analysis based on space-time filtering. J. Atmos. Sci., 69, 17-34.

Yokoi, S., M. Katsumata, and K. Yoneyama, 2014: Variability in surface meteorology and air-sea fluxes due to cumulus convective systems observed during CINDY/DYNAMO. J. Geophs. Res. Atmos., 119, 2064-2078.

Yoneyama, K., C. Zhang, and C. N. Long, 2013: Tracking 
pulses of the Madden-Julian oscillation. Bull. Amer. Meteor. Soc., 94, 1871-1891.

Yu, J.-Y., C. Chou, and J. D. Neelin, 1998: Estimating the gross moist stability of the tropical atmosphere. $J$. Atmos. Sci., 55, 1354-1372.

Yu, L., and R. A. Weller, 2007: Objectively analyzed air-sea heat fluxes for the global ice-free oceans (19812005). Bull. Amer. Meteor. Soc., 88, 527-539.

Zhang, C. D., 1996: Atmospheric intraseasonal variability at the surface in the tropical western Pacific Ocean. $J$. Atmos. Sci., 53, 739-758.

Zhang, C. D., 2005: Madden-Julian Oscillation. Rev. Geophys., 43, RG2003, doi:10.1029/2004RG000158.

Zuluaga, M. D., and R. A. Houze Jr., 2013: Evolution of the population of precipitating convective systems over the equatorial Indian Ocean in active phases of the Madden-Julian oscillation. J. Atmos. Sci., 70, 27132725. 